\title{
Future changes in seasonal temperature over Pakistan in CMIP6
}

Rizwan Karim ${ }^{1}$, Guirong Tan ${ }^{1, *}$, Brian Ayugi ${ }^{1,2}$, Hassen Babaousmail ${ }^{3}$, Fei Liu ${ }^{4}$, Hamida Ngoma $^{1,5}$, Victor Ongoma ${ }^{6}$

${ }^{1}$ Key Laboratory of Meteorological Disaster, Ministry of Education (KLME)/Joint International Research Laboratory of Climate and Environment Change (ILCEC)/Collaborative Innovation

Center on Forecast and Evaluation of Meteorological Disasters (CIC-FEMD), Nanjing,

University of Information Science and Technology, Nanjing 210044, China

${ }^{2}$ Jiangsu Key Laboratory of Atmospheric Environment Monitoring and Pollution Control, Collab orative Innovation Center of Atmospheric Environment and Equipment Technology, School of E nvironmental Science and Engineering, Nanjing University of Information Science and Technolo gy, Nanjing 210044, China

${ }^{3}$ Binjiang College of Nanjing University of Information Science and Technology, Jiangsu, Wuxi, China

${ }^{4}$ School of Atmospheric Sciences and Guangdong Province Key Laboratory for Climate Change and Natural Disaster Studies, Sun Yat-sen University/ Southern Marine Science and Engineering Guangdong Laboratory, Zhuhai 519082, China

${ }^{5}$ Makerere University, Department of Geography, Geoinformatics and Climatic Sciences, P.O. Box 7062, Kampala Uganda

${ }^{6}$ International Water Research Institute, Mohammed VI Polytechnic University, Lot 660, Hay Moulay Rachid, Ben Guerir, 43150, Morocco

*Corresponding author: tanguirong@ nuist.edu.cn

\section{Abstract}

The present study analyzed seasonal (i.e., Dec-Jan [DJF] and June - August [JJA]) temperature change for the near (2025-2054) and far future (2070-2099) under SSP245, SSP370, and SSP585 scenarios over Pakistan. The anomalies, Mann-Kendall trend tests, Sequential Mann-Kendall trend test (SQMK), and probability density frequency (PDF) analysis were used to investigate future mean temperature variations. The DJF season projected higher increase in temperature in the northern $\left(3.8^{\circ} \mathrm{C}, 5.1{ }^{\circ} \mathrm{C}\right.$ and $\left.6.5^{\circ} \mathrm{C}\right)$, followed by central regions $\left(3.8^{\circ} \mathrm{C}, 4.9{ }^{\circ} \mathrm{C}\right.$ and $\left.6.4{ }^{\circ} \mathrm{C}\right)$ under SSP245, SSP370 and SSP585 scenarios, respectively. The central region is likely to record significant increase in JJA $\left(3.0^{\circ} \mathrm{C}, 4.4{ }^{\circ} \mathrm{C}\right.$ and $\left.5.4{ }^{\circ} \mathrm{C}\right)$ mean temperature in far future under the given SSP scenarios. Compared to historical (PDF), the far future DJF temperature changes revealed significant higher warming over northern, central and then over southern regions under most of SSP scenarios. The southern regions are projected to possible rise in far future JJA 
temperatures by $2.7^{\circ} \mathrm{C}, 3.3{ }^{\circ} \mathrm{C}$ and $4.3^{\circ} \mathrm{C}$, under SSP245, SSP370 and SSP585, respectively. The PDFs for JJA further verify the highest positive abrupt shift in temperature across the central region and then southern region. The future diverse seasonal temperature changes supports further examination of the associated mechanisms and factors responsible for temperature changes to address climate change.

Key words: CMIP6, Temperature, Projections, Trends, Pakistan

\section{Introduction}

Global warming alters climate characteristics, strongly linked to human well-being, biodiversity, water resources, agriculture, and the environment (Bessou et al., 2009; Stocker et al., 2013). The warming is considered the first-order indicator of increasing greenhouse gases concentrations (Hansen et al., 2010). A global mean surface temperature has increased by 0.74 ${ }^{\circ} \mathrm{C}$ during the $21^{\text {st }}$ century under different range of possible representative concentration pathway (RCP) scenarios and is likely to rise by $1.1-6.4{ }^{\circ} \mathrm{C}$ in under current business as usual scenario (IPCC, 2014).

The projected rise in temperature will result in intense, frequent, and long-lasting catastrophes of droughts, floods, heatwaves, and glacial lake outburst floods (GLOFs) across many parts of the globe (Abas et al., 2017; Cook et al., 2018; Trenberth., 2011). The expected impacts of temperature upsetting will be more noticeable and disastrous to earth's life and ecosystems than other climate variables (Perkins et al., 2018). The knowledge of the future projected changes in temperature helps mitigate the associated impacts (O'Neill et al., 2016).

General circulation models (GCMs) used in climate predictions have evolved from atmospheric global circulation models (AGCMs) and reliable climate change estimates. Various participating modeling groups developed the latest generation of models released under the Climate Models Intercomparison Project (CMIP) $6^{\text {th }}$ phase (Eyring et al., 2016). The ScenarioMIP in CMIP6 experimental was designed to facilitate a wide range of integrated studies through the scenario process of shared socioeconomic pathways (SSPs) across the $21^{\text {st }}$ century (Eyring et al., 2016). According to Almazroui et al. (2020a), CMIP6 models also exhibit higher climate sensitivity to greenhouse gases (GHG) forcing than CMIP5 models. A higher sensitivity may overestimate or bias the trends for past and future, which could be reduced by recalibrating 
models and the use of ensembles (Jimenez-de-la-Cuesta and Mauritsen, 2019; Tokarska et al., 2020).

Several studies have investigated the mean temperature projections across diverse regions and timescales to estimate the exposure of the environment and communities to eminent future warming scenarios (Grose et al., 2020; Almazroui et al. 2020a, b; Mishra et al., 2020). To illustrate this, Grose et al. (2020) found a higher magnitude of $6.5^{\circ} \mathrm{C}$ in CMIP6 models ensemble projections than CMIP5 $\left(5.1{ }^{\circ} \mathrm{C}\right)$ for SSP585 (RCP8.5) by the end of the $21^{\text {st }}$ century over Australia. Over Africa, Almazroui et al. (2020a) projected mean annual temperature for 20302059 (2070-2099) by $1.2{ }^{\circ} \mathrm{C}\left(1.4{ }^{\circ} \mathrm{C}\right), 1.5^{\circ} \mathrm{C}\left(2.3{ }^{\circ} \mathrm{C}\right)$, and $1.8{ }^{\circ} \mathrm{C}\left(4.4{ }^{\circ} \mathrm{C}\right)$ for the SSP1-2.6, SSP2-4.5, and SSP5-8.5, respectively. Recently, Mishra et al. (2020) in a bias corrected projections study projected an increase in maximum and minimum temperatures by $3{ }^{\circ} \mathrm{C}$ to $4{ }^{\circ} \mathrm{C}$ and $3.5^{\circ} \mathrm{C}$ to $5.5^{\circ} \mathrm{C}$ under SSP585 by the end of the $21^{\text {st }}$ century over south Asia.

Pakistan is ranked among the most vulnerable nation $\left(8^{\text {th }}\right)$ to climate change impacts across the globe (Eckstein, 2019). A few model based future projections have focused on mean temperature change and variability over Pakistan (Iqbal and Zahid, 2014; Ali et al., 2015; Babar et al., 2016; Rehman and Ali, 2018; Almazroui et al., 2020b). Existing studies have mainly centered over the broader Asian region or focused on extreme climate based on climate indices. For instance, Almazroui et al. 2020b conducted a study using CMIP6 multimodel ensemblebased projections for annual and seasonal mean temperature over South-Asian countries. The study established various changes for SSP126 for near (2030-2049), mid (2060-2069), and far (2080-2099) periods as $1.0^{\circ} \mathrm{C}, 1.4^{\circ} \mathrm{C}$ and $1.3^{\circ} \mathrm{C}$; for the SSP 45 were $1.1{ }^{\circ} \mathrm{C}, 2.0^{\circ} \mathrm{C}$ and $2.6^{\circ} \mathrm{C}$ and for the SSP585 were recorded to be $1.4{ }^{\circ} \mathrm{C}, 3.1{ }^{\circ} \mathrm{C}$ and $4.6{ }^{\circ} \mathrm{C}$, respectively. Using CMIP5, Ali et al. (2019) projected an increase in frequencies and magnitudes for warm extremes and decreased cold extremes during the $21^{\text {st }}$ century. Further, studies (Khan et al., 2020; Sajjad and Ghaffar, 2019a) projected a significant increase in the frequency of summer days (6 days increase $)$ and a mean maximum $\left(1.3{ }^{\circ} \mathrm{C}\right)$ and minimum $\left(1.9{ }^{\circ} \mathrm{C}\right)$ temperature over the northern parts Pakistan.

Hydrologically, summer and winter seasons are crucial to Pakistan's agriculture, industry, and domestic use. About 51-80 \% of the country's water demand is met by glacial and rainwater stored in the northern mountainous regions (Nabeel and Athar, 2019). The water resources are anticipated to deplete rapidly under the warming phenomenon in the coming years. 
Rapid urbanization, deforestation, and industrialization in the southern region may increase the warming intensity, frequency, and span in the coming years. The aforementioned phenomenon could lead to of floods, flash floods, GLOFs, droughts, heatwaves across various spatiotemporal scales across Pakistan (McSweeney et al., 2008).

This study is designed to project the future changes in mean seasonal temperature over Pakistan based on CMIP6 multimodel ensemble. This work will be the first attempt in using CMIP6 models to project temperature changes and trends across Pakistan. The outcomes from this work will help to strengthen and improve the current climate change mitigation and adaptation strategies. The rest of the paper is organized as follows: Section two highlights model description and the techniques employed while section three delineates results of the study. Section four is mainly about discussions and implication of the study. Finally, conclusion and recommendations are presented in section five.

\section{Materials and Methods}

\subsection{Study Area}

Pakistan is situated on the western edge of South Asia, between latitudes $23^{\circ}-37.5^{\circ}$ $\mathrm{N}$ and $61^{\circ}-78^{\circ} \mathrm{E}$ longitudes, covering an area of $880,940 \mathrm{~km}^{2}$ (Figure 1). The country's terrain and geography is mainly rugged, reaching higher altitudes (8216 m high K2 peak) in northern and northwestern mountainous ranges. The Himalaya-Karakoram-Hindukush ranges are known as the water towers and lifeline of South Asia due to its vast glaciers, fresh water lakes, rivers and tributaries (Archer and Fowler, 2004). The central and southern regions are mostly hilly on the western sides, and the eastern and southeastern areas consist of Indus Plains (Sarfaraz, 2014). The majority of the area's climate is arid (60\%) and semiarid, including the vast deserts of Thal, Thar, and the Cholistan in the south; and hyper-arid lands and plateau in the southwestern part of Balochistan province (Farooqi et al., 2005). Temperature over Pakistan ranges from as low as $<0{ }^{\circ} \mathrm{C}$ in northern regions to the soaring temperatures of $>35{ }^{\circ} \mathrm{C}$ over southern regions (Nasim et al., 2018). In recent decades, the seasonal trend of temperature has increased over northern Pakistan in all seasons (Asmat et al., 2018; Ullah et al., 2019a). The strong, frequent and prolonged heatwaves have persistently increased over southern, central and eastern parts of Pakistan (Ullah et al., 2019b; Sajjad and Ghaffar, 2019). 


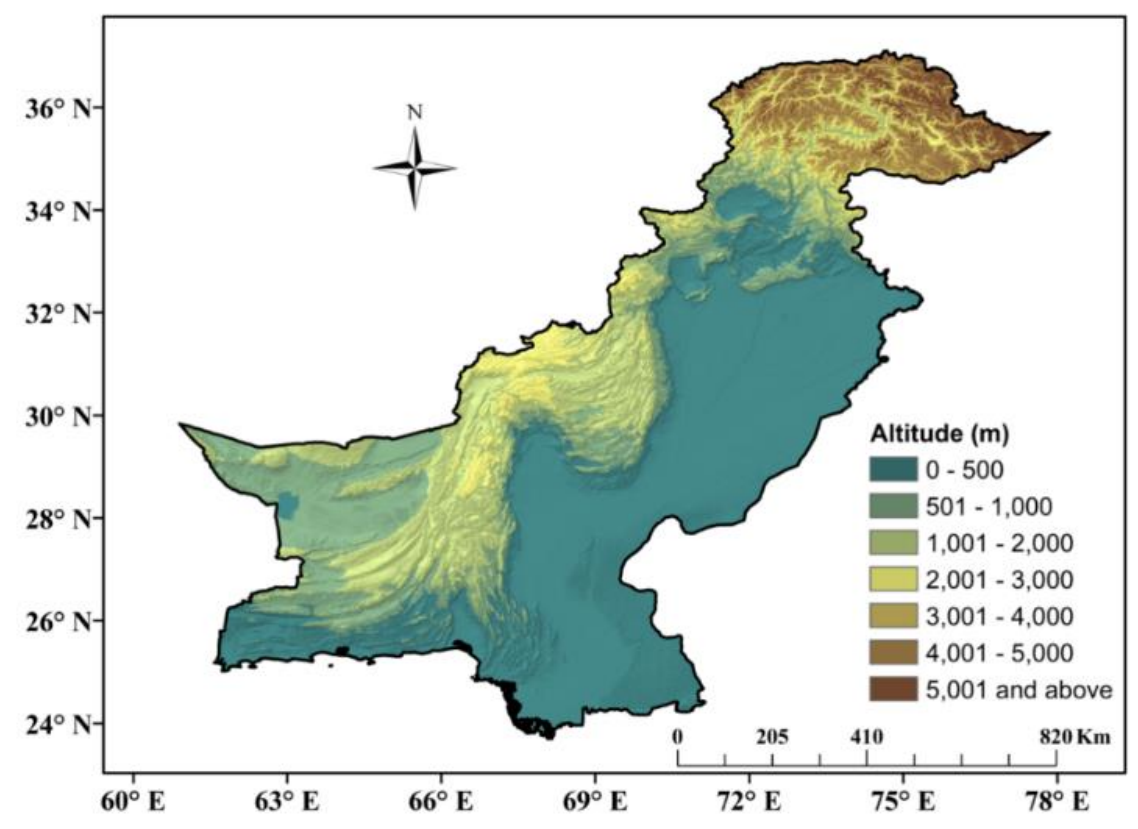

Figure 1. Map of Pakistan $\left(61^{\circ}\right.$ E- $78^{\circ}$ E and $\left.23^{\circ} \mathrm{N}-37.5^{\circ} \mathrm{N}\right)$ showing elevation $(\mathrm{m})$ above sea level for different regions.

Pacific Decadal Oscillation (PDO), Atlantic Multidecadal Oscillation (AMO), El Niño and La Niña phenomenon under various ocean-land-atmosphere mechanisms also influence the regional and global land surface temperature (Guan et al., 2017).

\subsection{Models' Calibration and Standardization}

This study utilized an ensemble of six models from CMIP6 datasets that are verified (Karim et al., 2020) to accurately simulate the observed temperature over Pakistan. The individual model description and relevant information is given in Table 1. The model's data for three SSPs: SSP2-4.5, SSP3-7.0 and SSP5-8.5, was accessed from the CMIP6 website https://esgf-node.llnl.gov/search/cmip6. All the sub-members for each model were first merged then standardized for standard units and calendar time. Since all models had varying horizontal resolutions, they were regridded to a common grid of $1.4^{\circ} \times 1.4^{\circ}$ using the nearest neighbor interpolation technique (Vermeulen et al., 2017). This approach gives a good representation of hilly terrain (Mallika et al., 2015).

Further, monthly multimodel ensemble (MMEs) in the three SSP scenarios were generated by taking the mean of utilized models for each scenario. It is well understood that one 
most common applications of ensembles is to separate the external forcing from internal variability (Milinski et al., 2019). According to Frankcombe et al., 2015, models' realizations show internal variability and forced response time series. This study considered only the first realization (r1i1p1f1) for each model, based on data availability at the time of carrying this study. According to Maher et al. (2018) there is no clear consensus on how large and ensemble should be for any given application or the questions to be addressed. To understand the changes in temperature across diverse geography, the study area was divided into northern $\left(70^{\circ} \mathrm{E}-78^{\circ}\right.$ and $\left.33.6^{\circ} \mathrm{N}-37.5^{\circ} \mathrm{N}\right)$, central $\left(60^{\circ} \mathrm{E}-75^{\circ} \mathrm{E}\right.$ and $\left.28.5^{\circ} \mathrm{N}-33.5^{\circ} \mathrm{N}\right)$ and southern $\left(60^{\circ} \mathrm{E}-72^{\circ} \mathrm{E}\right.$ and $23^{\circ} \mathrm{N}-$ $28.5^{\circ} \mathrm{N}$ ) regions.

To understand the temperature changes with time progression, two time periods i.e., 2025-2054 (near future) and 2070-2099 (far future), were defined from the monthly-scale MMEs. The two-time scales projected the Dec - Feb (DJF) and Jun - Aug (JJA) season mean temperature changes and trends across Pakistan.

\subsection{Spatio-temporal changes in future projections}

Usually, the future warming estimates and uncertainties in models and spread in projections is conveyed in probabilistic estimates like mean and range (Brunner et al., 2020). The annual temporal projections for 2015-2100 over the whole, northern, central, and southern regions of Pakistan were determined by subtracting annual projection values from the historical (1985-2014) value. The seasonal temporal projections over 2015-2100, near future, and far

future were calculated by subtracting future series values for each specific season from the historical mean value for each specific season. The spatial JJA and DJF projections changes over the whole of Pakistan for the two timelines were determined by subtracting future seasonal mean from historical (1985-2014) seasonal mean value for each pixel.

\subsection{Mann-Kendall test}

Mann-Kendall (MK) trend test used to investigate and its changes (Mann, 1945; Kendall, 1975. The Mann-Kendall test has been commonly used in numerous trend studies (Iqbal and Zahid, 2014; Amin et al., 2017; Ongoma et al., 2018a; Ali et al., 2019; Ayugi et al., 2020; Ayugi and Tan, 2019) for temporal trend analysis. MK trend does not require normal distribution in datasets to handle outliers and missing values. The test hypothesis states that the trend does not exist $\left(\mathrm{H}_{0}\right)$, and the trend does exist $\left(\mathrm{H}_{1}\right)$ in a time series. MK correlation coefficient or Kendall's 
Tau establishes trend in a time series. The strength of the trend is defined by the magnitude of the MK test statistic, where greater magnitude exhibits more robust trends, and lesser magnitudes show a weaker trend.

\subsection{Trend slope estimation}

The JJA and DJF season spatial trends were calculated using the Sen's Slope estimation technique to see the trend changes. The Sen's Slope estimates the true slope for a linear trend in a time series (Sen, 1968).

\subsection{Abrupt Changes in Trends}

The Sequential Mann Kendall (SQMK) test is applied to detect trend turning points (Mann, 1945). The abrupt changes are estimated by the progressive $(u)$ and retrograde $\left(u^{\prime}\right)$ series in time series. The $u$ values counted from first to last while $u$ ' values counted from last to first value of time series. The intersection of $u(t i)$ and $u^{\prime}(t i)$ shows a potential turning point. If an intersection occurs at threshold level \pm 1.96 (95\% confidence level) of z statistic, such a trend turning point is considered significant. The decreasing values of $u(t i)$ and $u$ '(ti) indicate a negative trend, while the increasing values represent a positive trend in the time series. When at least one of the reduced variable values is greater than \pm 1.96 , a new trend beginning is considered (Chatterjee et al., 2016). The JJA and DJF temporal seasonal datasets for near future and far future are treated with SQMK to detect the abrupt change in the series.

\subsection{Probability Density Function for mean temperature distribution}

This study also focuses on the likelihood of an outcome (density distribution) for changes in MME based seasonal mean temperature changes/ dispersion from the mean value for different spatio-temporal scales. In probability density function (PDF), an integral function is applied on continuous random variables with many intervals to find the chance of occurrence for different values in the intervals (Ongoma et al., 2018b; Watterson, 2008). In this study, kernel smoothing density distribution was utilized following work by Farooqui and Soomro (1984), where kernel smoothing had an excellent ability to define and classify likely changes and rare events. The DJF and JJA seasonal data for near and far future timelines were treated for the probability density estimation over different spatial scales of Pakistan. 
Table 1. List of available CMIP6 models used in ensemble-based projection of future mean temperature, displaying their origin, resolution, and variant label year. Model CESM had r2i1p1f1 variant label available for all scenarios in CMIP6 repository at time of following this study.

\begin{tabular}{lllll}
\hline No & Model Name & \multicolumn{1}{c}{ Institute } & $\begin{array}{c}\text { Resolution } \\
\text { (lon._lat.) }\end{array}$ & $\begin{array}{c}\text { Variant } \\
\text { Label }\end{array}$ \\
\hline 1. & CanESM5 & $\begin{array}{l}\text { Canadian Centre for Climate Modeling and Analysis } \\
\text { (Canada). }\end{array}$ & $2.8^{\circ} \times 2.8^{\circ}$ & r1i1p1f1 \\
2. & CESM2 & National Centre for Climate Research (USA). & $1.3^{\circ} \times 0.9^{\circ}$ & r1i1p1f1 \\
3. & CESM2-WACCM & National Centre for Climate Research (USA). & $1.3^{\circ} \times 0.9^{\circ}$ & r1i1p1f1 \\
4. & MPI-ESM1-2-HR & Max Planck institute for meteorology (Germany). & $0.9^{\circ} \times 0.9^{\circ}$ & r1i1p1f1 \\
5. & MPI-ESM1-2-LR & Max Planck Institute for Meteorology (Germany). & $1.9^{\circ} \times 1.9^{\circ}$ & r1i1p1f1 \\
6. & MRI-ESM2-0 & Max Planck Institute for Meteorology (Germany). & $1.1^{\circ} \times 1.1^{\circ}$ & r1ilp1f1 \\
\hline
\end{tabular}

\section{Results}

\subsection{Annual temporal projected changes in mean temperature}

The projected changes in mean temperature over different Pakistan regions show a warming tendency across all regions (Figure 2). The projected change for the whole of Pakistan (Figure 2a) is expected to increase above 3.2, 5.1 and $7.0^{\circ} \mathrm{C}$ under SSP 245, 370, and 585 at the end of this century. Similarly, the mean temperature over northern Pakistan (Figure 2b) is projected to warm by $3.1{ }^{\circ} \mathrm{C}, 5.6^{\circ} \mathrm{C}$ and $7.5{ }^{\circ} \mathrm{C}$. Further, the central regions (Figure 2c) project increasing temperature throughout the $21^{\text {st }}$ century by $3.2{ }^{\circ} \mathrm{C}, 5.0{ }^{\circ} \mathrm{C}$ and $7.2{ }^{\circ} \mathrm{C}$ under the SSP 245, 370, and 585 scenarios compared to historical mean temperature. The southernmost parts (Figure 2d) of the country also estimate an increase in temperature by the magnitude of $2.9^{\circ} \mathrm{C}$, $4.4{ }^{\circ} \mathrm{C}$ and $6.1^{\circ} \mathrm{C}$ at the end of the $21^{\text {st }}$ century under the SSP 245,370 , and 585 scenarios. 

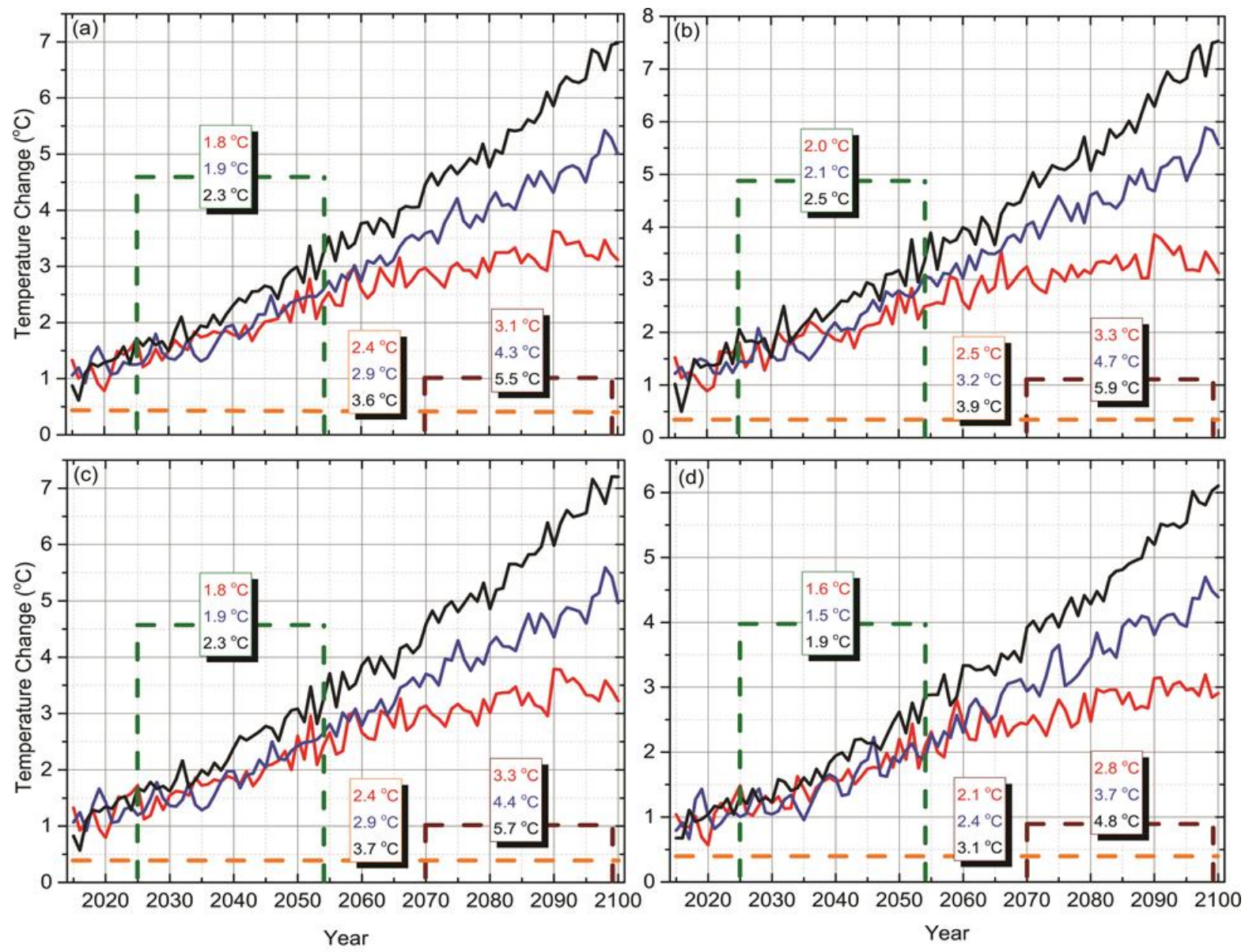

SSP245 SSP370 - SSP585

Figure 2. The annual projected changes in surface mean temperature $\left({ }^{\circ} \mathrm{C}\right)$ over the whole (a) Pakistan, (b) northern, (c) central, and (d) southern regions defined for the 2015-2100 timeline based on multimodel ensemble mean (MME) under SSP 245, 370, and 585 scenarios. The green and wine color linked boxes represent the mean changes projected for the near future and far future timelines, respectively. Orange color line linked box show projections for 2015-2100 timescale mean projections.

Overall, the projected changes under all three SSP scenarios are strongest over the northern and then central regions. In an exciting development, a slight decrease in the SSP245 temperature changes between 2090 and 2100 across the country and sub-regions are visible under the likely robust climate mitigation strategies. Moreover, the average projection changes for two time slices (blue and red dash-lined boxes) clearly show a higher 

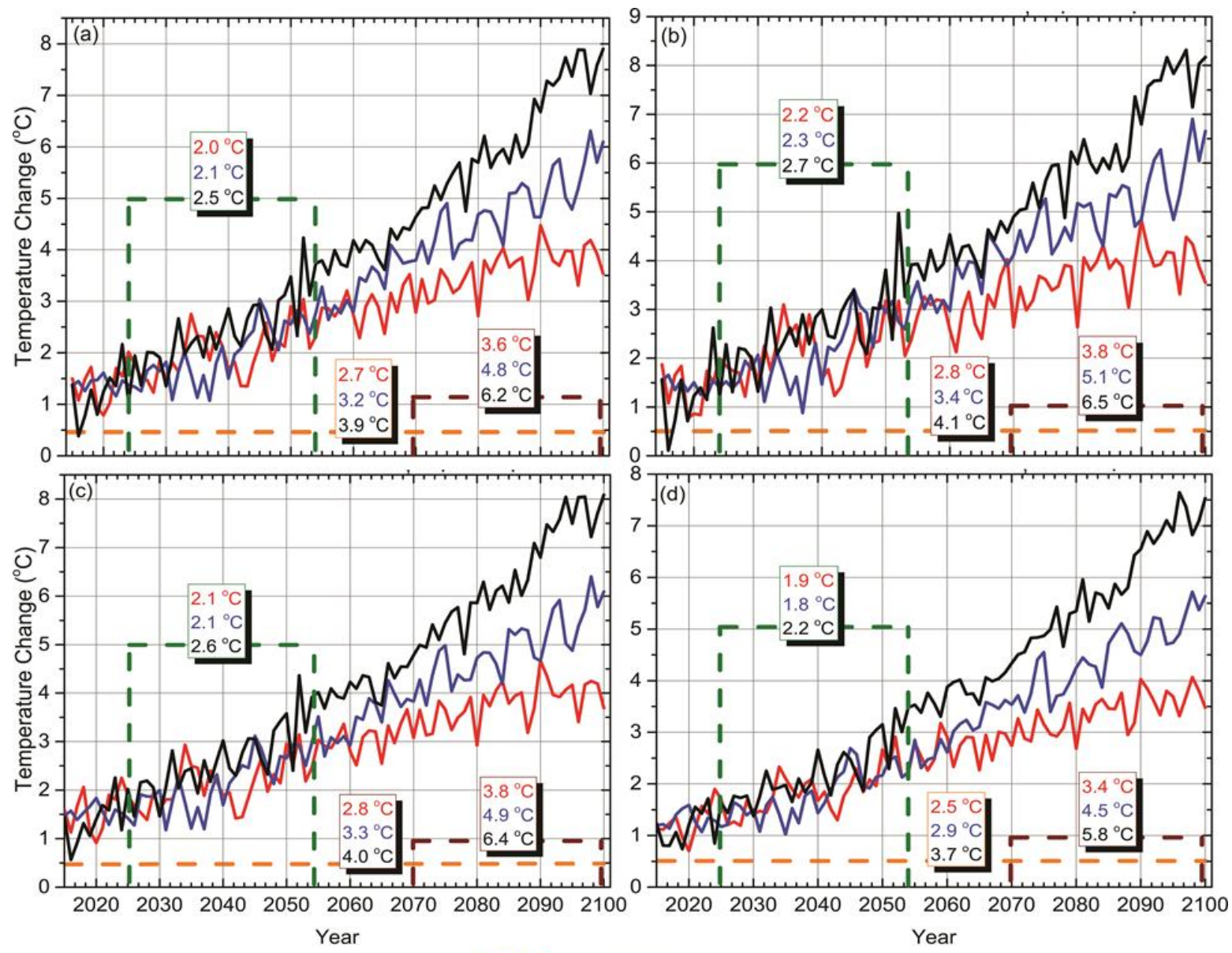

SSP245 SSP370 - SSP585

Figure 3. The DJF projected changes in temperature $\left({ }^{\circ} \mathrm{C}\right)$ over all (a) of Pakistan, (b) northern, (c) central, and (d) southern regions defined for the 2015-2100 period based on multimodel ensemble mean (MME) under SSP 245, 370, and 585 scenarios. The green and wine color line linked boxes represent the mean changes projected for the near future and far future DJF. Orange color line linked box show projections for 2015-2100 timescale mean projections.

rate of increase in the far future under all three scenarios across the country, particularly over northern and central regions. Zelinka et al. (2020) observed the equilibrium climate sensitivity (ECS) i.e., temperature response to $\mathrm{CO}_{2}$ doubling, and found it higher in CMIP6 models with values spanning from 1.8 to $5.6 \mathrm{~K}$ across $27 \mathrm{GCMs}$ and exceeding $4.5 \mathrm{~K}$ in 10 models. This insignificant increase is primarily due to more substantial positive cloud feedback on warming from reducing extratropical low cloud coverage, water content, and the albedo process. According to Rangwala et al. (2010), a higher warming tendency over higher altitudes may be 
due to increased downward long wave radiation, surface specific humidity, and absorbed solar radiation under a decrease in snow cover extent.

\subsection{Projected JJA and DJF temporal changes in mean temperature}

This is projected increase in mean temperature during 2015-2100, near future and far future periods in DJF season for the whole Pakistan and regions (Figure 3). The projections over the entire country (Figure 3a) shows the SSP 245, 370 and 585 reaching $3.5{ }^{\circ} \mathrm{C}, 6.1{ }^{\circ} \mathrm{C}$, and 7.9 ${ }^{\circ} \mathrm{C}$ the end of the $21^{\text {st }}$ century. The northern regions (Figure 3b) under SSP 245, 370, and 585 scenarios are projected with a sharp rise of $3.6{ }^{\circ} \mathrm{C}, 6.7^{\circ} \mathrm{C}$ and $8.2{ }^{\circ} \mathrm{C}$ units higher by the end of the century. Under the SSP245, 370, and 585 scenarios, central regions (Figure 3c) project an increase by $3.7^{\circ} \mathrm{C}, 6.1^{\circ} \mathrm{C}$ and $8.1^{\circ} \mathrm{C}$ by the end of the century. The southern parts (Figure $3 \mathrm{~d}$ ) also show positive changes in SSP 245,370 , and 585 projections by $3.5^{\circ} \mathrm{C}, 5.6^{\circ} \mathrm{C}$ and $7.5^{\circ} \mathrm{C}$ by the end of the $21^{\text {st }}$ century. The projection change for DJF during 2015-2100 is highest in the northern region and then central regions under all SSP scenarios. It is also visible that mean temperature projection change during DJF for the far future is higher than the near future across all regions and all three SSP scenarios. Moreover, the northern regions gave the highest projections changes for near and far future periods and all three SSP scenarios and central regions.

Temporal projected changes for JJA season over regions of Pakistan show an increase in temperature (Figure 4). Over the whole of Pakistan (Figure 4a), a rise in temperature by $3.0^{\circ} \mathrm{C}$, $4.2{ }^{\circ} \mathrm{C}$ and $6.4{ }^{\circ} \mathrm{C}$ is projected at the end of the century under SSP 245, 370, and 585 scenarios. Similarly, over northern Pakistan (Figure 4b), an increase by $2.6{ }^{\circ} \mathrm{C}, 4.6{ }^{\circ} \mathrm{C}$ and $7.0{ }^{\circ} \mathrm{C}$ is projected under SSP245, 370 and 585 scenarios at the end of this century. Under the SSP 245, 370 and 585 scenarios, the central regions show (Figure 4c) an increase in temperature by $3.1^{\circ} \mathrm{C}$, $4.2{ }^{\circ} \mathrm{C}$ and $6.4{ }^{\circ} \mathrm{C}$ by the end of the $21^{\text {st }}$ century. The southern regions (Figure $4 \mathrm{~d}$ ) also project a rise in temperature as $3.2{ }^{\circ} \mathrm{C}, 3.8^{\circ} \mathrm{C}$ and $5.5{ }^{\circ} \mathrm{C}$ units for JJA under SSP245, 370 and 585. The projections for the 2015-2100 period JJA are highest over northern regions then central regions under all three SSP scenarios. In another seasonal analysis for two time slices, it is visible that JJA mean temperature projections under SSP245, 370 and 585 for the far future are higher than near future years. 

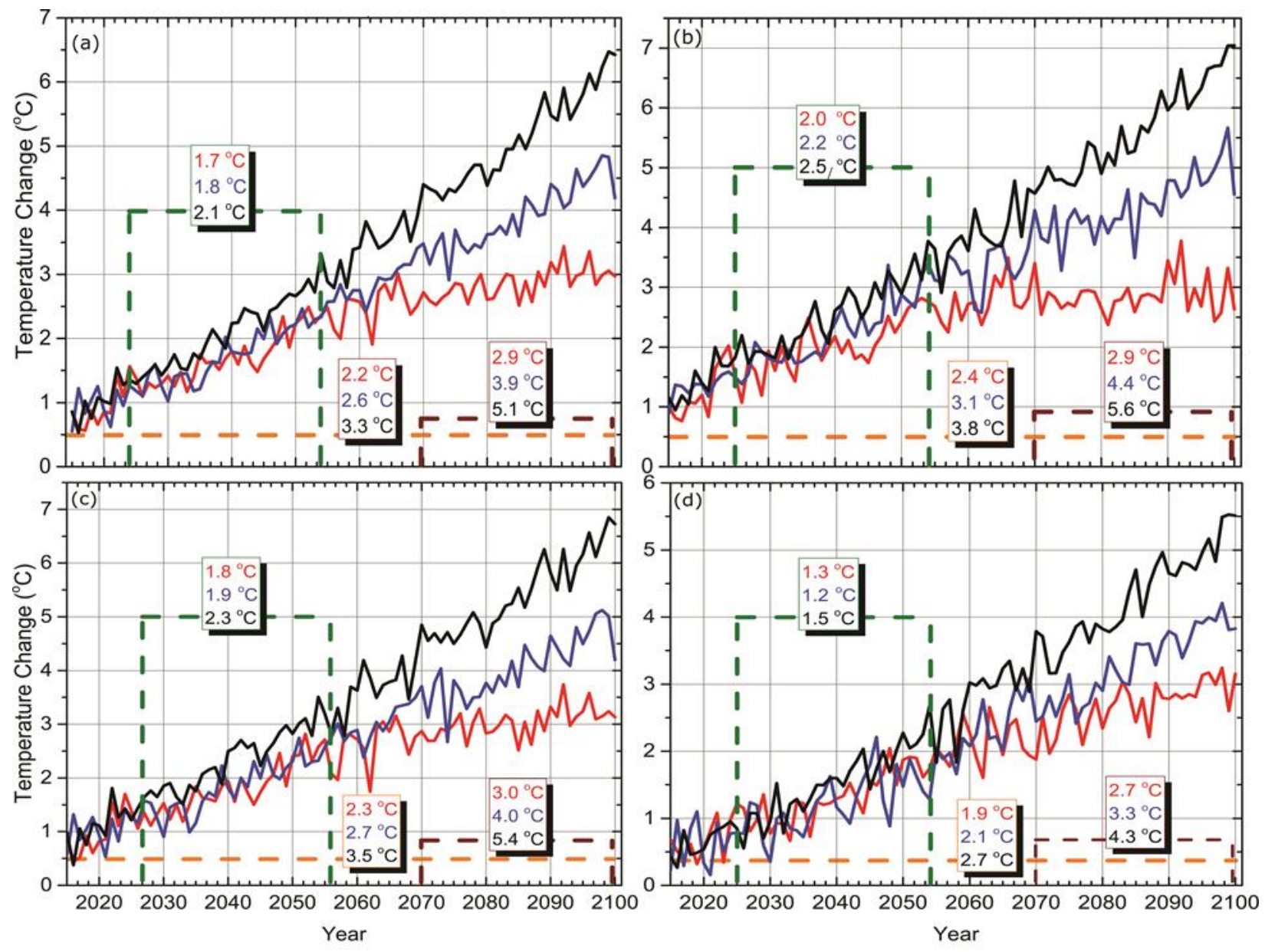

SSP245 SSP370 - SSP585

Figure 4. Same as figure 3 but for JJA (summer) season over all (a) of Pakistan, (b) northern, (c) central, and (d) southern regions defined.

Further, the JJA projections are highest over northern regions and then over central regions for both near and far future time scale under all three SSP scenarios. It is can also be observed that 2015-2100, near and distant future timescale based temporal projected changes for DJF over all the regions and under all three SSP scenarios are higher than the corresponding JJA projections. The projections over northern areas for 2015-2100, near and far future periods, are higher among in sub-regions during DJF season than JJA. The elevation-dependent phenomenon (EDW) phenomenon could significantly cause temperature rise over higher altitudes at seasonal (winter and autumn) and annual scales under the snow-albedo positive feedback, nighttime cloud cover, higher mid-troposphere water vapor, aerosols' concentration, and land-use changes (Pepin et al., 2015; Wu and Liu, 2016). 


\subsection{Spatial temporal changes for near and far future}

The spatial distribution of changes in projections for DJF and JJA mean temperature for the near future and far future is shown in Figures 5 and 6. The results show diverse positive changes in temperature projections compared with historical 1985-2014 mean temperature. During DJF (Figure 5a), the near future time scale project an increase of 1 to $3{ }^{\circ} \mathrm{C}$ over most parts of Pakistan under SSP245, and is projected to reach $4{ }^{\circ} \mathrm{C}$ at few points in the north. The southern regions project $1{ }^{\circ} \mathrm{C}$ increase for the time scale mentioned. However, in the far future, DJF temperature (Figure $5 \mathrm{~b}$ ) will reach 3 to $5{ }^{\circ} \mathrm{C}$ with higher $\left(4\right.$ to $5{ }^{\circ} \mathrm{C}$ ) over northern and central regions. The southern regions project a 2 to $4{ }^{\circ} \mathrm{C}$ temperature increase during the far future period. The DJF projected temperatures change under SSP370 (Figure 5c) scenarios for near future timescale yield an increase of 1 to $3{ }^{\circ} \mathrm{C}$ across the country with small patches in north projecting a $\left(4{ }^{\circ} \mathrm{C}\right)$ increase in temperature. The coastal regions show the lowest $\left(2{ }^{\circ} \mathrm{C}\right)$ increase in projected temperature for the near future. For the DJF far future projections, most of the northern and central regions project (Figure 5d) an increase of 4 to $6{ }^{\circ} \mathrm{C}$, with minor patches in the north projecting up to $7{ }^{\circ} \mathrm{C}$ increase. The southern regions show an increase of $4{ }^{\circ} \mathrm{C}$ particularly over coastal southwestern areas. During 2025-2054 DJF season under the SSP-585 (Figure 5e) scenario, a temperature increases of 1 to $4{ }^{\circ} \mathrm{C}$ is projected across the country with few northern regions projecting a temperature increase of up to 3 to $4{ }^{\circ} \mathrm{C}$. The southern regions comparatively project less increase in temperature $2{ }^{\circ} \mathrm{C}$ to $3{ }^{\circ} \mathrm{C}$ and coastal regions showing 2 ${ }^{\circ} \mathrm{C}$. Over the far future, the DJF temperature under the SSP-585 scenario (Figure 5f) is projected to increase by the highest magnitudes among all corresponding and other scenarios during both timescales. An increase of 5 to $7{ }^{\circ} \mathrm{C}$ over most of the country with some parts in center and north show a temperature increase of $8{ }^{\circ} \mathrm{C}$ to $9{ }^{\circ} \mathrm{C}$ higher by 2054 compared to $1985-2014$ mean temperature. The southern regions project 6 to $7{ }^{\circ} \mathrm{C}$ increase in temperature, with coastal regions predicting a 4 to $5{ }^{\circ} \mathrm{C}$ increase in temperature.

The JJA spatial projections changes for near and far future time scale show (Figure 6) varying projections of mean temperature changes for different the SSP scenarios. For the far future, the JJA mean temperature under the SSP 245 is projected (Figure 6a) to reach a 1 to $3{ }^{\circ} \mathrm{C}$, with mainly $3{ }^{\circ} \mathrm{C}$ over northern regions while rest of country projecting a 1 to $2{ }^{\circ} \mathrm{C}$ increase. In the far future, the temperature change (Figure 6b) under SSP245 is projected to reach 2 to $4{ }^{\circ} \mathrm{C}$, 

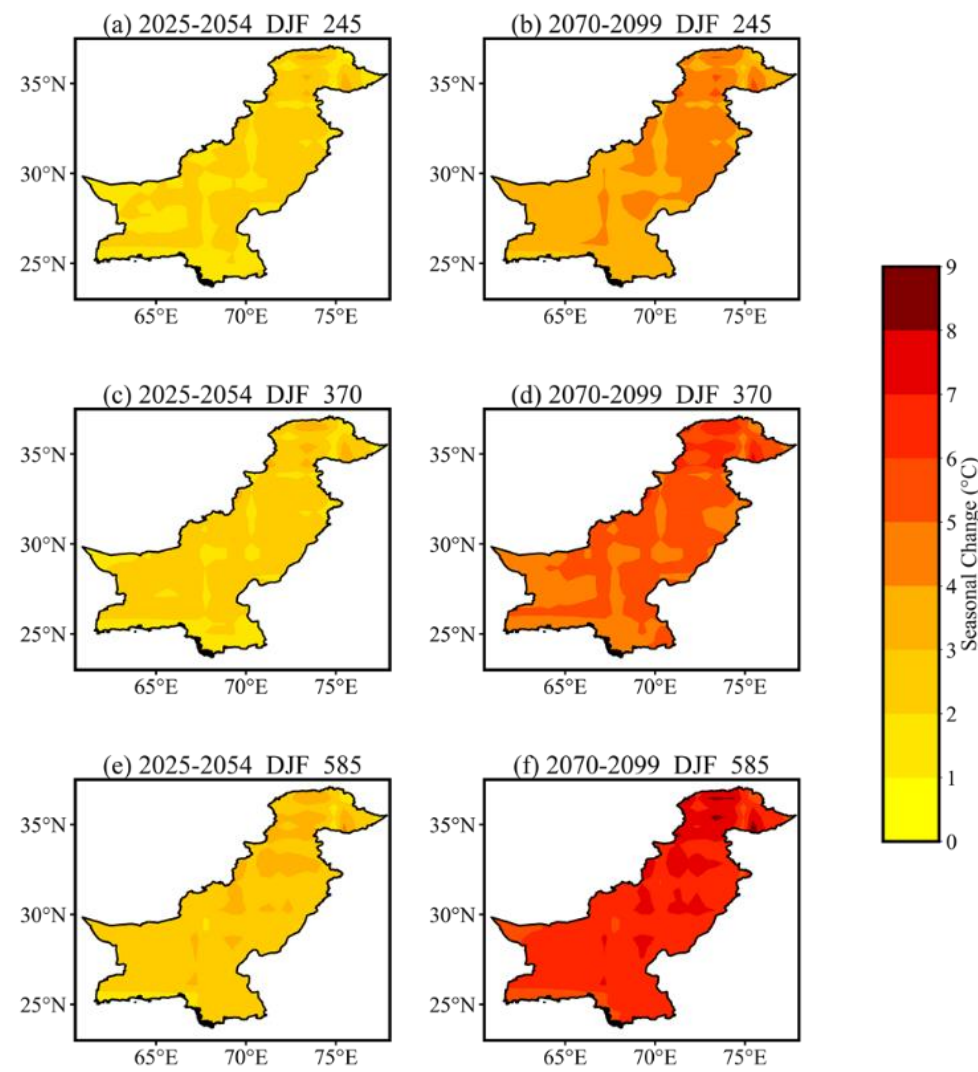

Figure 5. Spatial distribution of projected changes in DJF surface mean temperature $\left({ }^{\circ} \mathrm{C}\right)$ during near future (left panel) and the far future (right panel) under the SSP-245 (top panel), SSP-370 (middle panel) and SSP-585 (bottom) scenarios.

with higher temperature over northern and central regions $\left(4^{\circ} \mathrm{C}\right)$. Some southwestern regions also show temperature reaching $4{ }^{\circ} \mathrm{C}$, while most of regions in south show temperature reaching $3{ }^{\circ} \mathrm{C}$.

The JJA mean temperature during 2025-2054 under SSP370 project a change of 1 to $3{ }^{\circ} \mathrm{C}$ across Pakistan (Figure 6c), with northern and southwestern regions projecting up to $3{ }^{\circ} \mathrm{C}$. The other southern parts show an increase by 0.1 to $2{ }^{\circ} \mathrm{C}$ for near future period for same season under SSP370. During the far future period, a higher increase of 3 to $5{ }^{\circ} \mathrm{C}$ across Pakistan (Figure $6 \mathrm{~d}$ ) under SSP370 is clearly visible. Results show that the northern and southwestern regions will experience higher increase in temperature, reaching $\left(4\right.$ to $\left.5^{\circ} \mathrm{C}\right)$. The central-eastern and most of the southern regions are projected to warm by $4{ }^{\circ} \mathrm{C}$ and $3{ }^{\circ} \mathrm{C}$. 

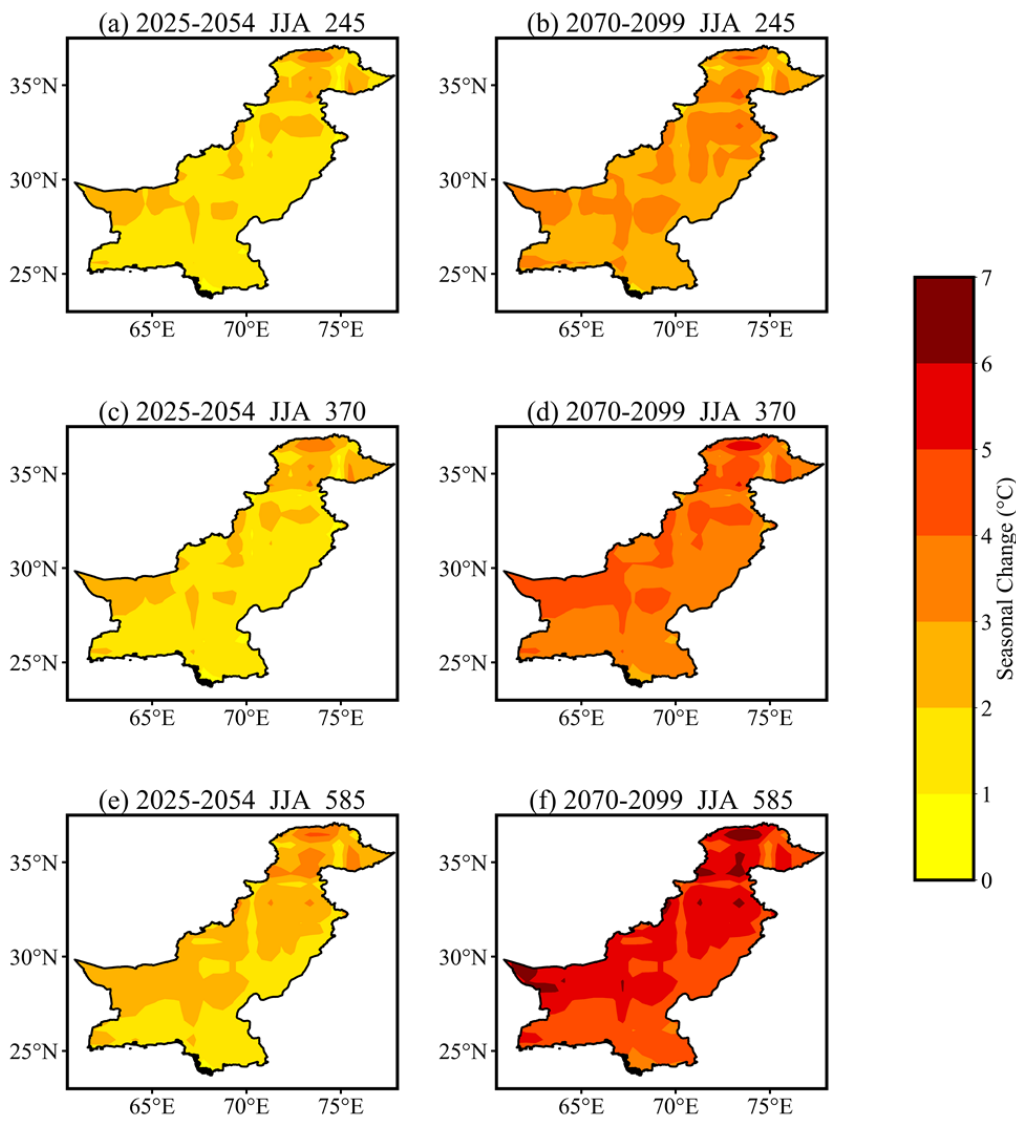

Figure 6. Same as Figure 5, but for JJA season

Under SSP585 scenario, JJA temperature change (Figure 6e) is projected to increase by 1 to $3{ }^{\circ} \mathrm{C}$ in the near future, with very few patches in northern areas reaching by $4{ }^{\circ} \mathrm{C}$. As expected, the projected warming is higher under SSP585 scenario as compared to SSP370. In the far future, the JJA mean temperature over Pakistan (Figure 6f) is projected to reach 4 to $6{ }^{\circ} \mathrm{C}$. Many regions in north, central and southwest of country show projection values of 5 to $6{ }^{\circ} \mathrm{C}$, although few places show a higher projection of $7{ }^{\circ} \mathrm{C}$ over the same regions. Most of the southern regions tend to expect an increase of 4 to $5{ }^{\circ} \mathrm{C}$, with western fringes reaching up to $6{ }^{\circ} \mathrm{C}$ under the SSP585 during JJA by end of $21^{\text {st }}$ century.

The spatial projection analysis for DJF and JJA during the near and far future period under SSP 245, 370, and 585 coincide with the corresponding temporal projected changes (Figures 3-4). Furthermore, from Figures 5 and 6, the DJF projections under all three scenarios and all periods are higher than the JJA season for similar scenarios and periods. The higher increase in temperature than in summer attests occurrence of climate change, mainly are a result 
of global warming. In the far future, the DJF and JJA projections show higher values under all three scenarios as compared to the case in near future. The far future SSP585 based DJF projections under projected the highest change in temperature among all SSP scenarios, timescales and seasons. The near future JJA projections under SSP245 exhibit the lowest increase in mean temperature among all seasons, scenarios and timescales.

\subsection{Future seasonal temporal trends}

The long-term annual and seasonal temporal trends for the near and far future are summarized in Table 2. For near future, the central regions project the highest positive annual trends of $0.35{ }^{\circ} \mathrm{C} /$ decade under SSP245, while the northern region project the highest annual trend increase of $0.55{ }^{\circ} \mathrm{C} /$ decade under the SSP 370 scenario. The central regions also show the highest annual trend increase under the SSP585 scenario. The near future trend increase for DJF is projected highest across northern region under SSP $245\left(0.30^{\circ} \mathrm{C} /\right.$ decade $)$ and SSP $370(0.61$ ${ }^{\circ} \mathrm{C} /$ decade), while

Table 2. The multimodel ensemble trend $\left({ }^{\circ} \mathrm{C} / \mathrm{dec}\right.$ ade $)$ values for surface mean temperature during annual, DJF and JJA scale for the near and far future.

\begin{tabular}{|c|c|c|c|c|c|c|c|c|c|c|c|c|}
\hline \multirow{3}{*}{ Scenarios } & \multicolumn{6}{|c|}{ 2025_2054 } & \multicolumn{6}{|c|}{ 2070_2099 } \\
\hline & \multicolumn{2}{|c|}{ Annual } & \multicolumn{2}{|c|}{ DJF } & \multicolumn{2}{|c|}{ JJA } & \multicolumn{2}{|c|}{ Annual } & \multicolumn{2}{|c|}{ DJF } & \multicolumn{2}{|c|}{ JJA } \\
\hline & $\Delta 10^{-1}$ & $\Delta / \boldsymbol{\nabla}$ & $\Delta 10^{-1}$ & $\Delta / \mathbf{V}$ & $\Delta 10^{-1}$ & $\Delta / \nabla$ & $\Delta 10^{-1}$ & $\Delta / \nabla$ & $\Delta 10^{-1}$ & $\Delta / \nabla$ & $\Delta 10^{-1}$ & $\Delta / \mathbf{V}$ \\
\hline \multicolumn{13}{|l|}{ Pakistan } \\
\hline SSP 245 & 0.33 & $\Delta *$ & 0.27 & ム* & 0.39 & $\Delta *$ & 0.18 & $\mathbf{\Delta}^{*}$ & 0.33 & $\mathbf{\Delta}^{*}$ & 0.15 & $\Delta *$ \\
\hline SSP370 & 0.45 & $\mathbf{\Delta}^{*}$ & 0.51 & $\Delta *$ & 0.42 & $\Delta *$ & 0.53 & $\Delta *$ & 0.55 & $\Delta *$ & 0.52 & $\Delta *$ \\
\hline SSP585 & 0.57 & $\Delta *$ & 0.58 & ム* & 0.56 & $\Delta *$ & 0.85 & $\mathbf{\Delta}^{*}$ & 1.11 & $\mathbf{\Delta}^{*}$ & 0.72 & $\Delta *$ \\
\hline \multicolumn{13}{|l|}{ Northern } \\
\hline SSP 245 & 0.30 & $\Delta *$ & 0.30 & $\Delta *$ & 0.42 & $\Delta *$ & 0.17 & $\mathbf{\Delta}^{*}$ & 0.33 & $\mathbf{\Delta}^{*}$ & 0.03 & $\Delta \neq^{*}$ \\
\hline SSP370 & 0.55 & $\Delta *$ & 0.61 & $\Delta *$ & 0.51 & $\Delta *$ & 0.54 & $\Delta *$ & 0.57 & $\mathbf{\Delta}^{*}$ & 0.43 & $\Delta *$ \\
\hline SSP585 & 0.57 & $\Delta *$ & 0.56 & $\Delta *$ & 0.58 & $\Delta *$ & 0.91 & $\Delta *$ & 1.11 & $\mathbf{\Delta}^{*}$ & 0.74 & $\Delta *$ \\
\hline \multicolumn{13}{|l|}{ Central } \\
\hline SSP 245 & 0.35 & $\Delta *$ & 0.25 & $\Delta *$ & 0.45 & $\Delta *$ & 0.18 & $\mathbf{\Delta}^{*}$ & 0.30 & $\mathbf{\Delta}^{*}$ & 0.15 & $\Delta *$ \\
\hline
\end{tabular}




\begin{tabular}{|c|c|c|c|c|c|c|c|c|c|c|c|c|}
\hline SSP370 & 0.48 & $\Delta *$ & 0.52 & $\Delta *$ & 0.42 & $\Delta *$ & 0.55 & $\Delta *$ & 0.59 & $\Delta *$ & 0.56 & $\Delta *$ \\
\hline SSP585 & 0.60 & $\Delta *$ & 0.60 & $\Delta *$ & 0.62 & $\Delta *$ & 0.86 & $\Delta *$ & 1.10 & $\Delta *$ & 0.74 & $\Delta *$ \\
\hline \multicolumn{13}{|l|}{ Southern } \\
\hline SSP 245 & 0.33 & $\Delta *$ & 0.27 & $\Delta *$ & 0.34 & $\Delta *$ & 0.20 & $\Delta *$ & 0.30 & $\Delta *$ & 0.25 & $\Delta *$ \\
\hline SSP370 & 0.35 & $\Delta *$ & 0.40 & $\Delta *$ & 0.30 & $\Delta *$ & 0.53 & $\Delta *$ & 0.63 & $\Delta *$ & 0.55 & $\Delta *$ \\
\hline SSP585 & 0.52 & $\Delta *$ & 0.55 & $\Delta *$ & 0.53 & $\Delta *$ & 0.75 & $\Delta *$ & 1.07 & $\Delta *$ & 0.78 & $\Delta *$ \\
\hline
\end{tabular}

Negative (positive) $\Delta \mathbf{1 0}^{-1}$ values indicate rate of decreasing (increasing) trend per decade. The $\mathbf{\Delta} / \mathbf{\nabla}$ signs indicate increase/decrease in the trend. The * and $\neq *$ denotes significant and insignificant trend at $95 \%$ confidence interval.

the central regions show highest annual trend increase under SSP585 (0.60 $\left.{ }^{\circ} \mathrm{C} / \mathrm{decade}\right)$ scenario. The near future JJA temperature highest trend increase under SSP245 scenario is projected over the central region $\left(0.45^{\circ} \mathrm{C} /\right.$ decade $)$. The JJA SSP370 highest trend increase is projected over the northern region $\left(0.51^{\circ} \mathrm{C} / \mathrm{decade}\right)$, and the highest trend increase under SSP585 is found over the central region $\left(0.62{ }^{\circ} \mathrm{C} /\right.$ decade $)$ near future JJA. In the near future, the central regions may experience higher annual and JJA trends increasing under SSP245 and SSP585, while the northern region may show a higher trend increase during DJF under the SSP245 and the SSP370 scenario. Significant changes are projected both in near future annual and seasonal temperature trends across all regions under all SSP scenarios.

The far future annual temperature trends over southern Pakistan under SSP245 are projected to be the highest at $0.20{ }^{\circ} \mathrm{C} /$ decade, while under SSP370 are increasing highest over central Pakistan $\left(0.55^{\circ} \mathrm{C} /\right.$ decade $)$. In the far future temperature, highest increasing temperature trends under SSP585 are estimated over northern Pakistan $\left(0.91^{\circ} \mathrm{C} /\right.$ decade $)$. In the far future, the DJF season mean temperature highest increasing trend under SSP245 is projected over northern Pakistan $\left(0.33^{\circ} \mathrm{C} /\right.$ decade $)$, while the highest DJF trend increase under SSP370 is forecasted over southern Pakistan $\left(0.63{ }^{\circ} \mathrm{C} /\right.$ decade $)$ region. The highest DJF trend increase under SSP585 is projected over the northern region $\left(1.11^{\circ} \mathrm{C} /\right.$ decade $)$, which is also the highest increase in trend for all seasons, timescales, and SSP scenarios utilized in the study. The JJA far-future trend increase under SSP245 is visible highest over southern regions $\left(0.25{ }^{\circ} \mathrm{C} / \mathrm{decade}\right)$ of Pakistan, while under SSP370 is found increasing the highest over central areas $\left(0.56^{\circ} \mathrm{C} / \mathrm{decade}\right)$ among all other sub-regions. The southern region project $\left(0.78{ }^{\circ} \mathrm{C} /\right.$ decade $)$ the highest trend JJA mean 
temperature under SSP585 scenario. In the far future, the northern region depicts the highest trend increase during DJF and annual scales, particularly under SSP585 scenarios. All the far future seasonal trends over all regions (except north Pakistan JJA trend under SSP245) are projected to increase significantly. The magnitude of increase in DJF temperature trend over all regions under all SSP scenarios (particularly under SSP585), and regions are higher than those in JJA.

Overall, the far future annual, DJF, and JJA trend under all SSP scenarios show a higher trend increase values projected in the near future. The far future annual trend magnitude under SSP245 has lower values than the near future values across all regions. This phenomenon and all other trend results for annual, DJF, and JJA trends changes coincide with the near and far future annual (Figure 2), DJF (Figure 3), and JJA (Figure 4) mean temperature projections across the time scales and all regions of Pakistan.

The near and far future abrupt shifts for DJF and JJA temporal trends over regions of Pakistan are drawn in supplementary Figures S1 to S6. In Figure S1a and Figure S1b, the near and far future SSP245 DJF exhibit significant positive abrupt trend shifts over Pakistan. Similarly, near and far future SSP370 DJF trends also show significant abrupt shifts over whole Pakistan. While SSP585 display an insignificant trend with abrupt shift in near and far future (Figure S1e and Figure S1f). Overall, most of the near and far future DJF trends significantly increase under SSP245 and SSP370 and insignificantly under SSP585 over whole Pakistan. During the JJA trend change analysis (Figure S2), except SSP245 far future JJA (Figure S2b) significant trend abrupt changes, all other scenarios in near and far future JJA season signal an insignificant trend abrupt shift over all of Pakistan. The far future SSP245 JJA trends only show the significant positive abrupt shift points, while rest of scenarios in near and far future show insignificant positive abrupt change.

The near and far future DJF and JJA mean temperature trend abrupt shifts under SSP245, SSP370 and, SSP585 over northern Pakistan are given in Figures S3 and S4. The near and far future DJF SSP245 trend shifts (Figure S3a and Figure S3b) show significant positive trend abrupt shifts. During near and far future SSP370, significant abrupt changes are noticeable in both (Figure S3c and Figure S3d) timescales. In near and far future SSP585 DJF trends, far future trends (Figure S3f) exhibit insignificant positive abrupt shifts. While all near and far future DJF trends under SSP585 over northern Pakistan are significantly increasing. The near 
and far future SSP245 JJA abrupt trend change analysis over northern Pakistan (Figure S4a and Figure S4b) detects insignificant positive abrupt shift in near and significant positive and negative shifts in far future. Similarly, near future SSP370 JJA trends show (Figure S4c) insignificant abrupt increase while the far future trend (Figure S4d) shows a significant positive abrupt shift. In near and far future SSP585 DJF trends (Figure S4e and Figure S4f), an insignificant trend abrupt increase is projected. The near and far future JJA trends over northern Pakistan are mostly insignificantly abruptly increasing (except far future SSP245 significant decreasing trend).

The SSP245, SSP370, and SSP585 centered near and far future trend abrupt shifts for DJF season over central Pakistan are given in Figure S5. The near future DJF SSP245 trends (Figure S5a) exhibits a significant abrupt trend increase while the far future trends (Figure S5b) also show significant positive abrupt shift. Similarly, the near and far future SSP370 DJF (Figure S5c and Figure S5d) yield significant positive trend abrupt shift over central Pakistan. However, in near and far future SSP585 DJF trends (Figure S5e and Figure S5f), an insignificant trend abrupt increase is projected. Most of near and far future DJF trend shift analysis over the central regions of Pakistan detect significant positive abrupt shifts under SSP245 and SSP370, while insignificant positive abrupt shifts in SSP585 scenarios. The near and far future JJA trend abrupt shifts under SSP245, SSP370, and SSP585 over central Pakistan are plotted in Figure S6. The SSP245 JJA trends show insignificant positive abrupt shifts (Figure S6a) for near future and significant positive shifts (Figure S6b) in far future trends over central Pakistan. The, near and far future SSP370 JJA trends (Figure S6c and Figure S6d) display an insignificant positive trend shift. Similarly, the near and far future SSP585 JJA trends (Figure S6e and Figure S6f) also yield insignificant abruptly increasing trends. Overall, most of JJA trends (except far future SSP245) display insignificant positive trend abrupt shifts.

The trend change analysis for near and far future DJF and JJA seasons under SSP245, SSP370, and SSP585 scenarios over southern Pakistan is presented in Figures S7 and S8. The near and far future SSP245 DJF seasons trends overall exhibit (Figure S7a and Figure S7b) significant positive abrupt shifts, although with few insignificant negative abrupt shifts in near future. The near and far future SSP370 DJF trends (Figure S7c and Figure S7d) show significant positive abrupt shifts across the region. The near and far future SSP585 DJF trend change detects (Figures S7e and Figure S7f) insignificant positive abrupt shifts. Most of JJA near and far future 
temperature abrupt trends are significantly increasing (SSP245 and SSP370) while under SSP585 show an insignificant abrupt increase. The SSP245 JJA season trends in near future display (Figures S8a and Figure S8b) significant trend abrupt shift over southern Pakistan. In the near future SSP370 JJA trends (Figure S8c), significant positive abrupt shifts are detected. While an insignificant positive abrupt shift in the far future (Figure S8d) trends are detected. Moreover, the near and future SSP585 JJA trends (Figure S8e and Figure S8f) abrupt shift analysis yield significant positive abrupt shifts over the region. Overall, the near and far future JJA trend abrupt shift analysis depicts insignificant abrupt positive shifts with only SSP245 showing significant positive abrupt shifts.

Overall, all the regions show significant abrupt trend shift points with a positive abrupt shift in near and far future DJF under all three SSP scenarios. The northern and central regions show the most significant abrupt trend changes in near and far future DJF under all SSP scenarios. The near and far future JJA trends abrupt changes under all SSP scenarios are found to be insignificantly positive (except southern region under SSP245 and SSP370) over most of the regions. Although, the near future JJA trends abrupt shifts under SSP245, and SSP370 are found significantly positive over southern Pakistan. The far future SSP245 JJA trend shift over northern Pakistan is the only scenario significant negative abrupt change is detected.

\subsection{Future spatial temperature trends}

The linear trend for near and far future DJF and JJA mean temperature under different SSP scenarios is estimated using Sen's slope estimator and presented in Figures 7 and 8 . The near future DJF positive trends under SSP245 range between 0.01 and $0.06{ }^{\circ} \mathrm{C} /$ year across Pakistan (Figure 7a). The northern regions project the highest increase (0.02 to $\left.0.06{ }^{\circ} \mathrm{C} / \mathrm{year}\right)$, while the central and southern regions project a positive trend of 0.001 to $0.04{ }^{\circ} \mathrm{C} / \mathrm{year}$ under the same scenario. Further, the far future trends (Figure 7b) increase under SSP245 as 0.02 to 0.06 ${ }^{\circ} \mathrm{C} /$ year across Pakistan with the highest increasing trends over north and south of the country. The near future DJF mean spatial temperature trends under SSP370 (Figure 7c) project a trend increases of 0.04 to $0.10{ }^{\circ} \mathrm{C} /$ year across Pakistan. The northern regions project highest trend increase (0.06 to $0.010{ }^{\circ} \mathrm{C} /$ year); central regions project a trend increase rate of 0.04 to 0.06 ${ }^{\circ} \mathrm{C} /$ year while southern predict the trends increase by 0.04 to $0.06{ }^{\circ} \mathrm{C} /$ year. The far future DJF trend (Figure $7 \mathrm{~d}$ ) increases by 0.04 to $0.10{ }^{\circ} \mathrm{C} /$ year under SSP370 and is widespread across the 
country. The northern and central regions project higher trend increases rates of 0.06 to 0.10 ${ }^{\circ} \mathrm{C} /$ year than the southern region $\left(0.04\right.$ to $\left.0.08{ }^{\circ} \mathrm{C} / \mathrm{year}\right)$ under the same scenario. The near future DJF spatial trend distribution (Figure 7e) under the SSP585 project increase in the range of 0.04 to $0.08{ }^{\circ} \mathrm{C} /$ year across the whole country. The central region shows the highest increase in trend (0.06 to $0.08{ }^{\circ} \mathrm{C} /$ year), while northern and southern regions predict a trend increase of 0.040 to $0.08^{\circ} \mathrm{C} /$ year. However, interestingly the far future DJF trends (Figure 7f) project a much higher increase $\left(0.10\right.$ to $>0.14{ }^{\circ} \mathrm{C} /$ year $)$ across the country under the SSP585 scenario. The northern
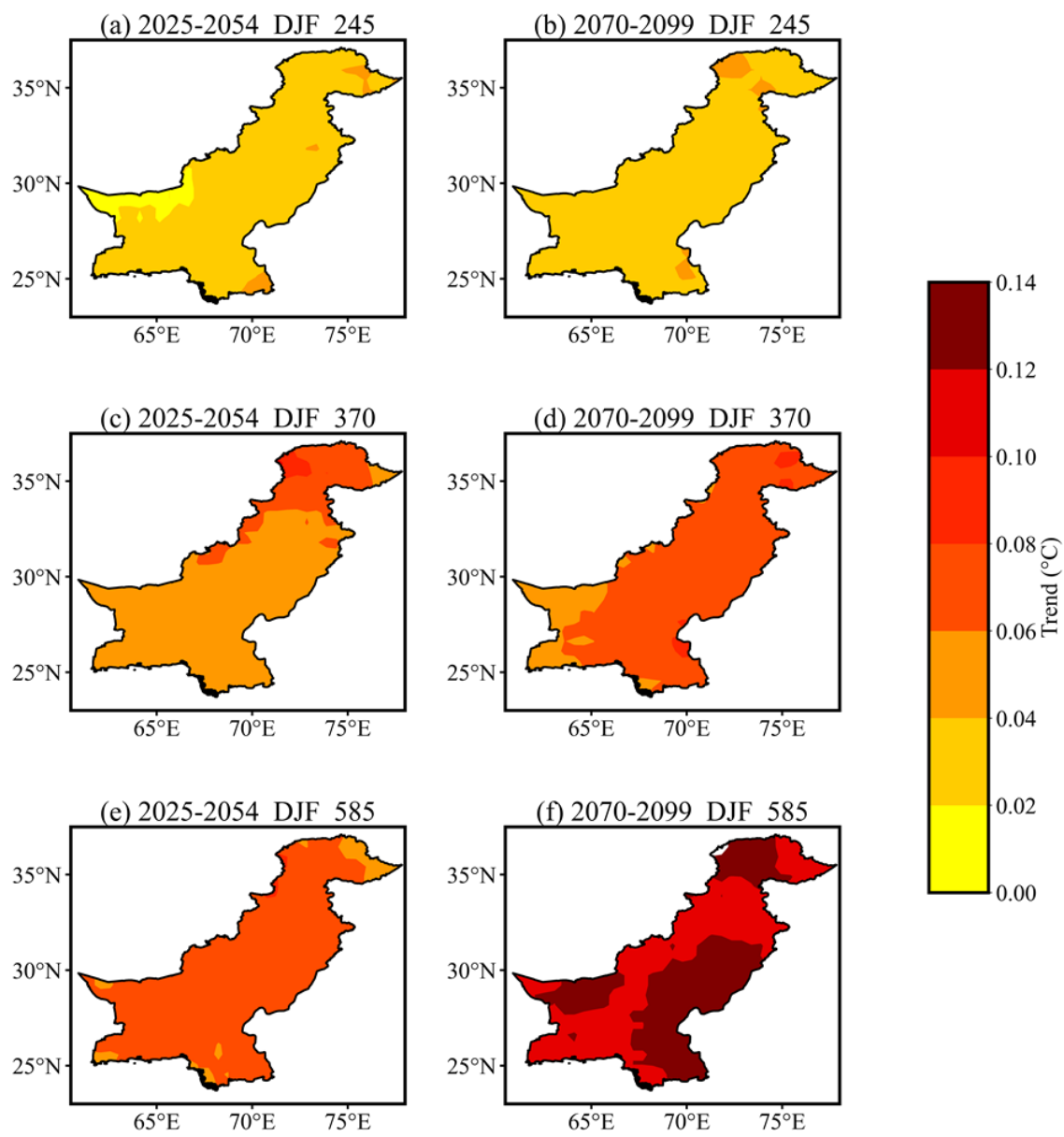

Figure 7. The spatial distribution of near and far future DJF (winter) surface mean temperature trend changes $\left({ }^{\circ} \mathrm{C} /\right.$ year) across Pakistan in near future (left panel) and far future (right panel) underSSP245 (top panel), SSP370 (middle panel), and SSP585 (lower panel).

regions project DJF trends increase of 0.10 to $>0.14{ }^{\circ} \mathrm{C} / \mathrm{year}$. While central and southern regions predict an increase in trends in a range of 0.10 to $0.14{ }^{\circ} \mathrm{C} / \mathrm{year}$, the central region predicts the higher distribution of trend than over the southern region. In the case of DJF 
trend changes for near and far future scales, the northern and central regions forecast higher rates of trend increase for almost all scenarios. Further, the SSP585 scenario in the near future and the far future timeline projects the highest magnitudes of DJF temperature trend increase. Moreover, the far future DJF trend values are higher than the near future DJF trend values under all three SSP scenarios.
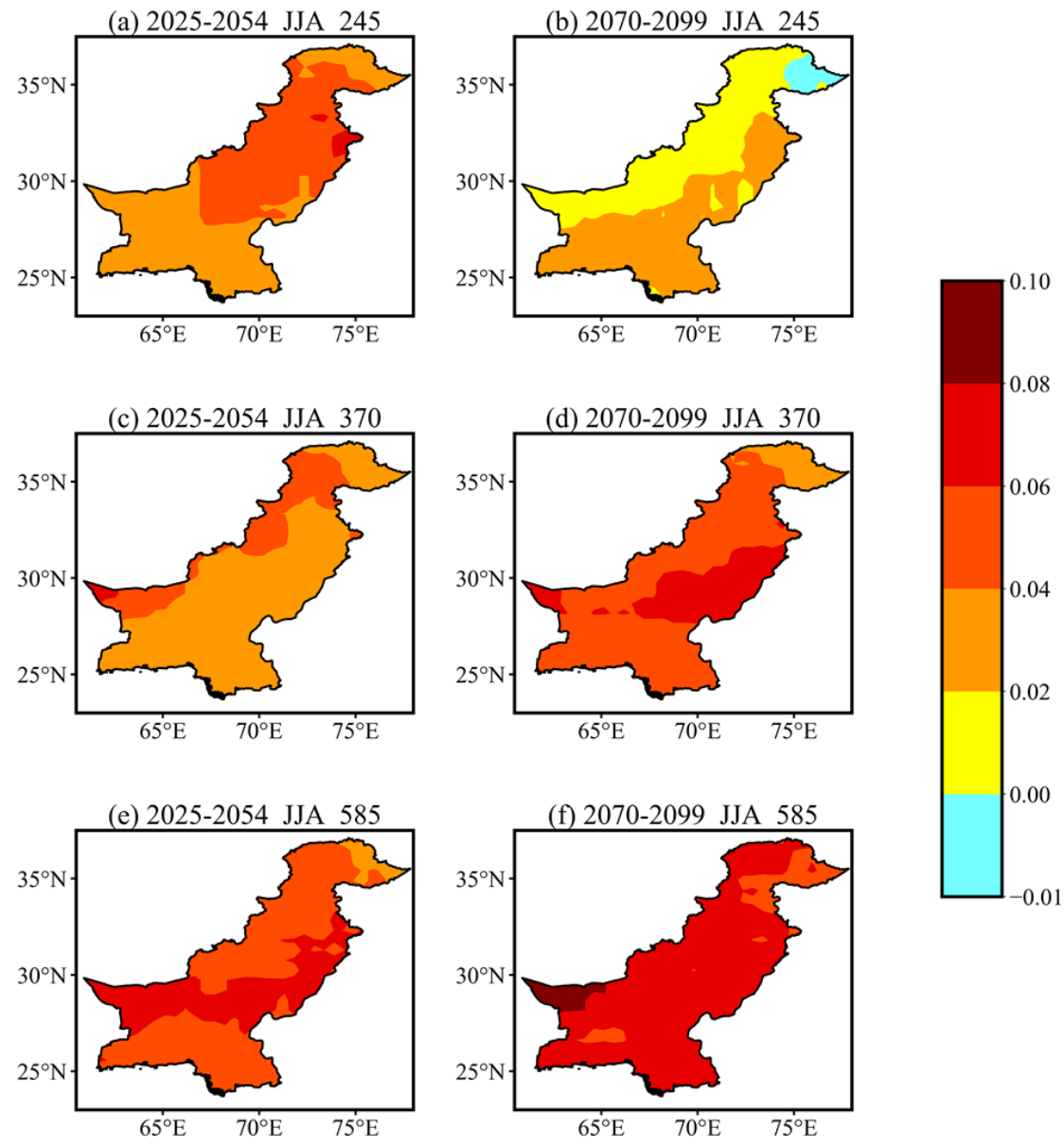

Figure 8. Same as figure 7, but for JJA season

The near and far future JJA season mean temperature spatial trend distribution over Pakistan under SSP245, SSP370, and SSP585 are presented in Figure 8. The JJA trend increases in the range of 0.02 to $0.08{ }^{\circ} \mathrm{C} /$ year under SSP245 (Figure 8a) in near future, with highest increase expected over central regions $\left(0.04\right.$ to $0.08{ }^{\circ} \mathrm{C} /$ year $)$. However, the far future JJA trends under SSP245 (Figure 8b) show a lesser increase ( 0.001 to $0.04{ }^{\circ} \mathrm{C} /$ year) over most areas.

Although the southern regions project a higher increase in trends $\left(0.001\right.$ to $0.04{ }^{\circ} \mathrm{C} /$ year $)$, a portion in northeastern region shows a slight decrease in trend (near to $0.01{ }^{\circ} \mathrm{C} / \mathrm{year}$ ). This 
decrease in trend is also in accord with its temporal trend (Table 2) output, and the temporal projections for JJA mean temperature (Figure 4f) over northern regions. There is also an agreement between this negative trend and the lesser temperature increase in the JJA spatial projections distribution (Figure 6b) over northeastern Pakistan in the far future. The JJA near future trend under SSP370 (Figure 8c) forecast an increase $\left(0.02\right.$ to $0.06{ }^{\circ} \mathrm{C} /$ year) over the whole country, with northern regions (0.02 to $0.06{ }^{\circ} \mathrm{C} /$ year) majorly showing a higher increase in trends. The far future JJA trend analysis (Figure 8d) under SSP370 projected an increase (0.04 to $0.08{ }^{\circ} \mathrm{C} /$ year) across all of Pakistan, with the central regions projecting the highest trend increase (0.04 to $0.08{ }^{\circ} \mathrm{C} /$ year). The JJA near future trends forecasts an overall increase over Pakistan (0.02 to $0.08{ }^{\circ} \mathrm{C} /$ year) under SSP585 (Figure 8e) scenario where the southern regions with the highest increase in trend. However, in far future JJA trend under the same scenario (Figure 8f); the southern regions may experience higher positive trends $\left(0.04{ }^{\circ} \mathrm{C} /\right.$ year to $\left.0.10{ }^{\circ} \mathrm{C} / \mathrm{year}\right)$ in mean temperature.

Overall, the JJA mean temperature near future trends shows a higher temperature increase over central regions majorly under SSP245 and SSP585 emission scenarios. However, in the far future timescale, it is evident that most of the southern and few central regions may see higher trends in temperature increase under all three SSP scenarios. The SSP585 scenario in the near future and far future exhibit the highest (values) trends increase among all scenarios and regions in the study.

\subsection{Future mean temperature probability density distribution}

The near and far future DJF and JJA season probability density function distributions for all Pakistan and over sub regions is plotted in Figures 9 to 12. The near future DJF (Figure 9a) shows positive shifts in all SSP scenarios against historical DJF mean temperature, particularly under SSP585 $\left(8-12^{\circ} \mathrm{C}\right)$. This positive shift indicates an increase in the near future DJF mean temperature. In far future DJF season (Figure 9b), all SSP scenarios yield the higher positive shifts in temperature than in near future, projecting higher DJF temperature occurrences by the end of the $21^{\text {st }}$ century. The near future JJA temperature (Figure 9c) under all SSP scenarios shows a positive shift against historical temperature, particularly under SSP585 (29-32 $\left.{ }^{\circ} \mathrm{C}\right)$ with higher probability of temperature increase. Further, far future JJA temperature (Figure 9d) under $\operatorname{SSP} 370\left(30.4-33.5{ }^{\circ} \mathrm{C}\right)$ and $\operatorname{SSP} 585\left(31.4-35{ }^{\circ} \mathrm{C}\right)$ show a higher positive shift than in near 
future JJA season, projecting a further higher temperature in the far future JJA season. Overall, near and far future seasonal temperature shift under all SSP scenarios is higher in DJF (particularly in the distant future) than in JJA.
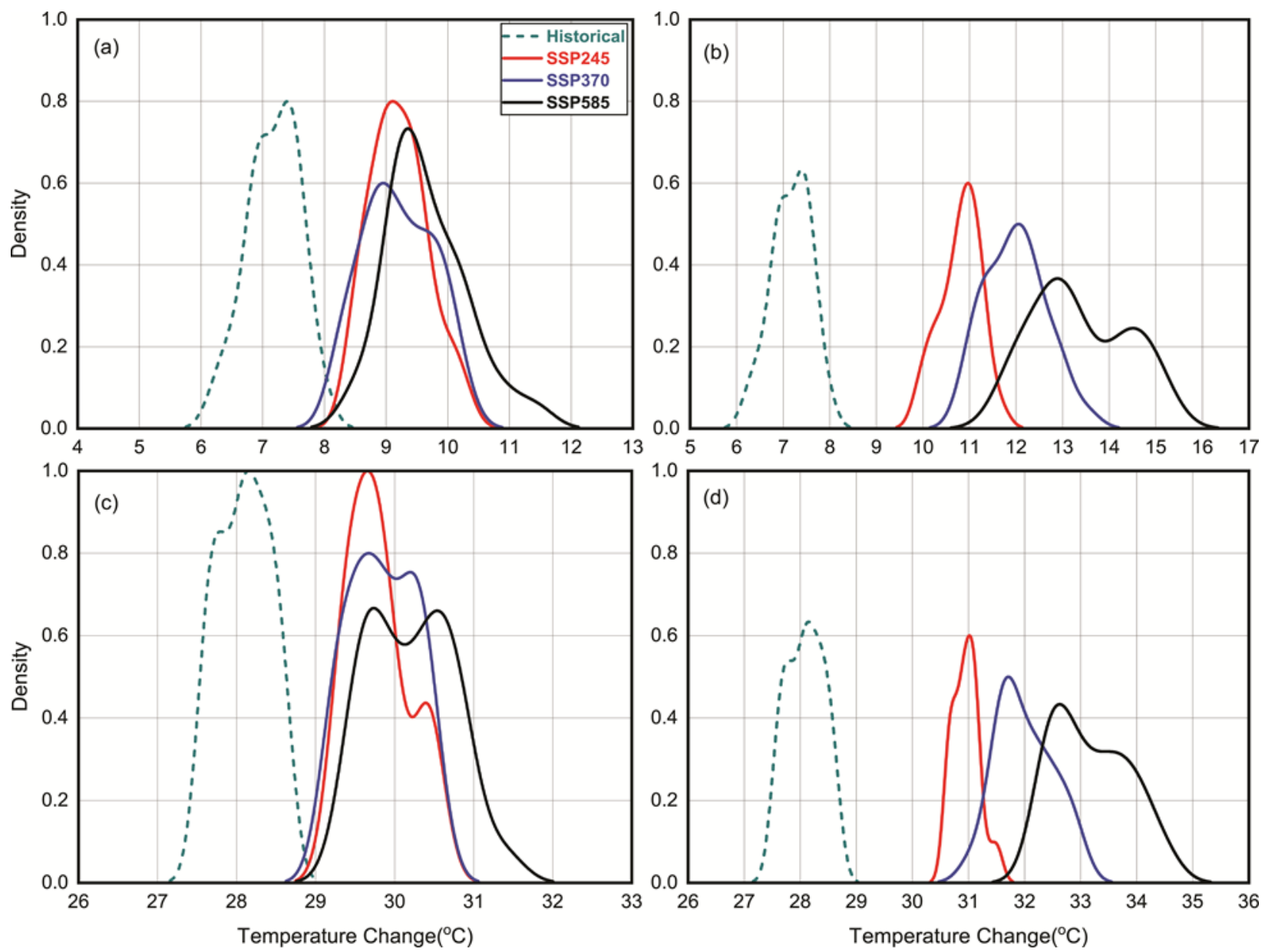

Figure 9. PDFs distributions in the near future (left panel) and far future (right panel) for $\operatorname{DJF}(\mathrm{a}, \mathrm{b})$ and JJA $(\mathrm{c}, \mathrm{d})$ season mean temperature $\left({ }^{\circ} \mathrm{C}\right)$ over Pakistan.

The near and far future seasonal mean temperature PDFs against historical mean changes under three SSP scenarios over northern Pakistan are shown in Figure 10. During the near future DJF (Figure 10a), a positive shift in temperature under all SSP scenarios is visible, with SSP585 $\left(-5.5-0.9^{\circ} \mathrm{C}\right.$ ) showing highest probability for shift. While, in far future DJF (Figure 10b), the PDF shows a higher positive shift, especially under SSP370 (-2.2 - $\left.2.8{ }^{\circ} \mathrm{C}\right)$ and SSP585 (-2.8 $4.5^{\circ} \mathrm{C}$ ) scenarios than in near future. 

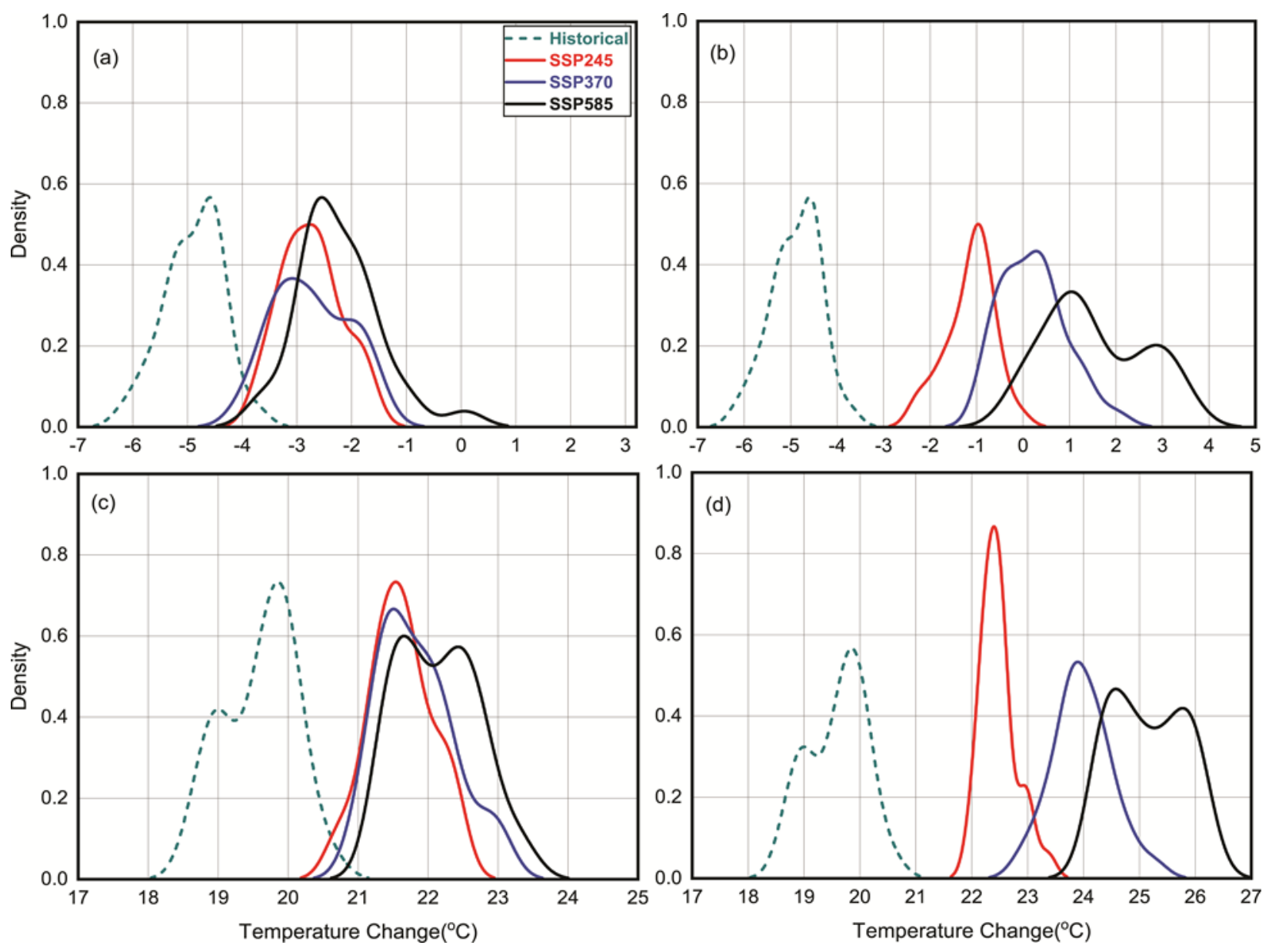

Figure 10. Same as Figure 9, but for Northern Pakistan.

The far future DJF higher positive shifts project higher temperature increases probability than in the near future. In near future JJA season (Figure 10c), a positive shift in temperature under all SSP scenarios; projecting temperature increase probability. In far future JJA season (Figure 10d), SSP370 (22.3 - $\left.25.8{ }^{\circ} \mathrm{C}\right)$ and SSP585 $\left(23.4-27^{\circ} \mathrm{C}\right)$ exhibit highest positive shift in temperature than in near future, indicating temperature increase. The far future SSP245 JJA temperature shows a minor positive shift $\left(21.8-23.7{ }^{\circ} \mathrm{C}\right)$ in mean temperature over northern Pakistan. Overall, near and far future DJF temperature change probability under all SSP scenarios is higher than in JJA. 

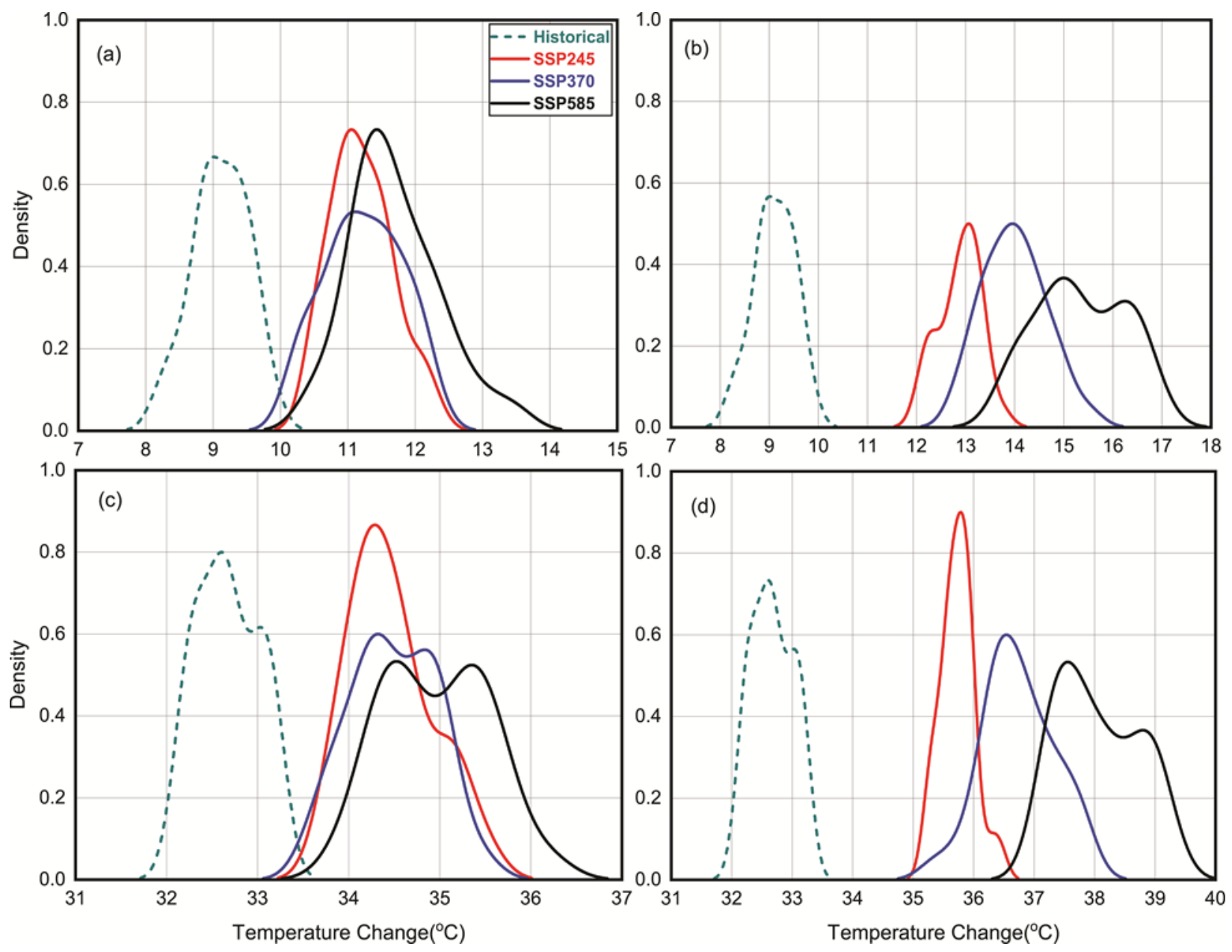

Figure 11. Same as Figure 9, but for Central Pakistan.

The near and far future seasonal mean temperature changes under SSP 245, SSP370, and SSP585 for the central Pakistan region are presented in Figure 11. The near future DJF season (Figure 11a) display a positive shift in temperature under all SSP scenarios, particularly, under SSP585 (10 - $\left.14^{\circ} \mathrm{C}\right)$ scenario. Similarly, during far future DJF season (Figure 11b), a strong temperature increase probability is visible under the SSP370 $\left(12-16{ }^{\circ} \mathrm{C}\right)$ and SSP585 (13 - 18 ${ }^{\circ} \mathrm{C}$ ), projecting a higher temperature trends than in near future DJF. The near future JJA temperature shows (Figure 11c) a positive shift probability under all SSP scenarios especially under SSP585 (33.3 - $\left.36.8{ }^{\circ} \mathrm{C}\right)$ over the central Pakistan. In far future JJA (Figure 11d), SSP370 $\left(34.9\right.$ - $\left.38.3{ }^{\circ} \mathrm{C}\right)$ and SSP585 (36.5 - $\left.39.9{ }^{\circ} \mathrm{C}\right)$ depict highest mean temperature increase probability than in near future. Moreover, temperature rise probability in the near and far future DJF is higher than in JJA under all SSP scenarios. 

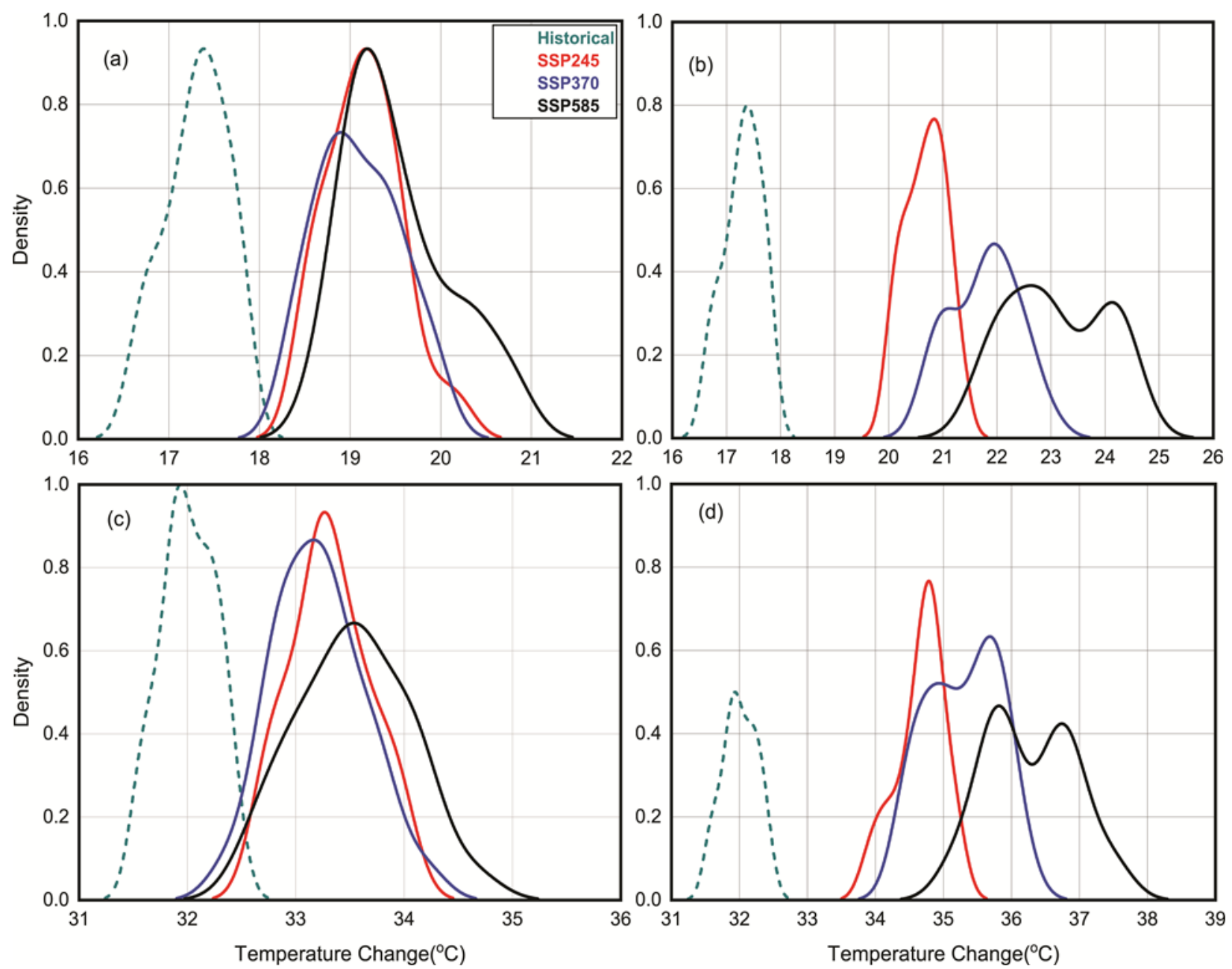

Figure 12. Same as Figure 9, but for Southern Pakistan.

The PDFs for near and far future DJF and JJA mean temperature over southern Pakistan are given in Figure 12. The near future DJF temperature PDF results (Figure 12a) identify a positive shift probability in temperature under all three scenarios, particularly under SSP585 (18 - $21.4{ }^{\circ} \mathrm{C}$ ) scenario. While the far future DJF (Figure 12b), display positive shift probability under SSP370 $\left(20-23.8^{\circ} \mathrm{C}\right)$ and SSP585 $\left(20.8-25^{\circ} \mathrm{C}\right)$, projecting an increase in temperature. The SSP245 $\left(19.8-21.8^{\circ} \mathrm{C}\right)$ shows a slight positive shift in temperature than near future. The probability of the temperature increase is higher in the far future DJF season than in near future. During the near future JJA, the PDFs exhibit (Figure 12c) a positive shift in temperature under all SSP scenarios over southern Pakistan. The far future JJA also shows a positive change (Figure 12d) under all SSP scenarios especially under all SSP585 $\left(34.5-38.2{ }^{\circ} \mathrm{C}\right)$ than in the near future. Overall, over southern Pakistan, the near and far future DJF season temperature shift probability is higher than the corresponding near and far future JJA season. 
Inclusively for all the regions, the near and far future DJF mean temperature shift (far future especially) PDFs under all SSP scenarios is found to be highest over northern Pakistan. This projects to the probable sharp increase in DJF temperature, and it also conforms to with the temporal projections (Figure 3b), temporal trends (Table 2), spatial projections (Figure 5), and spatial trends (Figure 7) analysis over the northern region. In contrast, the central regions during JJA season (near and far future) are found to show the highest positive shift in mean temperature among all regions, thus conforming to outputs of spatio-temporal projections (Figure 4d, Table 2, Figures 6 and 8) outputs. Similarly, southern regions display the probability of highest rise in temperature during near and far future JJA seasons, conforming to outputs of spatio-temporal projections (Figure 4-c, Figure 4-d, Table 2, Figure 6 and Figure 8) results.

\section{Discussion}

Until recent past, Pakistan has experienced a steady rise in mean temperature under the global warming phenomenon at various spatio-temporal scales (IPCC, 2014). The change in temperature reaching extreme levels has caused negative impacts on the ecosystems, human socioeconomics, and broadly the human wellbeing on large scale across Pakistan (Chaudhry et al., 2009). The impact of temperature increase is noted in other weather parameters/phenomena such as on precipitation under the atmospheric circulation like ENSO (Loo et al., 2015; Boucharel et al., 2011) on a global scale. The warming tendency of temperature is projected to continue with even higher magnitudes at seasonal and annual timescales over most Pakistan (Ali, 2019; Almazroui et al., 2020b). The new CMIP6 models-based climate projections for the $21^{\text {st }}$ century show warmer temperatures than CMIP5 based projections despite identical instantaneous radiative forcing (Wyser et al., 2020).

The current study focused on projected changes in DJF and JJA seasonal mean temperature over northern, central, and southern Pakistani regions for near and far future timescales. The current study projections and trend analysis identify the winter (DJF) mean temperature in the near, and far future under SSP245 $\left(2.0{ }^{\circ} \mathrm{C}\right.$ and $\left.3.6{ }^{\circ} \mathrm{C}\right), \operatorname{SSP} 370\left(2.1{ }^{\circ} \mathrm{C}\right.$ and $\left.4.8^{\circ} \mathrm{C}\right)$ and SSP585 $\left(2.5^{\circ} \mathrm{C}\right.$ and $\left.6.2^{\circ} \mathrm{C}\right)$ scenarios will significantly increase across all Pakistan. The summer (JJA) mean temperature in near and far future under SSP245 (1.7 and $\left.2.9{ }^{\circ} \mathrm{C}\right)$, SSP370 $\left(1.8^{\circ} \mathrm{C}\right.$ and $\left.3.9{ }^{\circ} \mathrm{C}\right)$ and SSP585 $\left(2.1^{\circ} \mathrm{C}\right.$ and $\left.5.9^{\circ} \mathrm{C}\right)$ is projected to increase across the central and southern region although with lesser rate of change than in DJF. Several studies (Almazroui et al., 2020b; Athar and Latif, 2018; Babar et al., 2016; Iqbal and Zahid, 2014; Sajjad 
and Ghaffar, 2019) found higher rates of increase in future winter and summer temperature Recently, Almazroui et al. (2020b) used CMIP6 multimodel ensemble for mean temperature over Pakistan. The study found that under the SSP245 scenario, JJA mean temperature will increase by $1.1{ }^{\circ} \mathrm{C}$ and $2.6{ }^{\circ} \mathrm{C}$, while under SSP585 as $1.4{ }^{\circ} \mathrm{C}$ and $4.6^{\circ} \mathrm{C}$ higher for $2030-2049$ and 20802099 timescale. During winter, the temperature increases of $1.2^{\circ} \mathrm{C}$ and $2.7^{\circ} \mathrm{C}$ is projected under SSP245, while under the SSP585 scenario, around $1.6^{\circ} \mathrm{C}$ and $5.4^{\circ} \mathrm{C}$ temperature will increase for 2030-2049 and 2080-2099 timescale. Additionally, Iqbal and Zahid (2014) under CMIP5 models projected an annual mean temperature higher than $5{ }^{\circ} \mathrm{C}$ under SSP585 with higher coverage over northern and central parts of the region. Ikram et al. (2016), predicted a positive change in summer season by $2.7^{\circ} \mathrm{C}$ and $2.7^{\circ} \mathrm{C}$ under RCP 4.5 and RCP8.5 scenario, respectively. On the other hand, the increase in temperature over winter will exceed that of summer season. The seasonal changes in temperature across diverse spatio-temporal scales may have severe implications for the environment, agriculture, water security, economy, and Pakistanis' wellbeing (Fatima et al., 2020; Khan et al., 2016). Over the years, Pakistan has experienced temperature rise, drought, pest disease, health issues causing changes in lifestyle (Hussain et al., 2018). Increased warming may also result in rainfall events, intensifying hydrological cycles in many Pakistan regions, leading to floods and droughts (Ali et al., 2019).

The northern region projects the highest rate of significant positive increase in winter mean temperature (Figure 3) under all SSP scenarios than in the summer (Figure 4) in comparison to the southern regions. The summer mean temperature rise is also insignificantly increasing over the northern region under SSP370 and SSP58. These results are the findings of related recent studies (Almazroui et al., 2020b; Asmat et al. 2018; Ikram et al., 2016; Rehman and Ali, 2018) which projected the highest temperature rise in the northern regions of Pakistan. The far future JJA season however, shows cooling trends over the northeast most part of the country. This is possibly linked to the enhanced aerosol effect on model parameterization and runs (Ikram et al., 2016). Most of the northern region comprises of high-altitude terrain with renowned mountain ranges of Hindukush, Karakorum, Himalayas, and Pamirs. These mountain ranges being globally one of the most sensitive ecosystems to climate change have, in recent years shown significant warming across the region and beyond (Fatima et al., 2020; Fowler and Archer, 2006). The phenomenon of elevation-dependent warming (EDW) is observed and projected as the significant phenomenon leading to abrupt warming at higher altitudes (Rangwala 
et al., 2010). The EDW phenomenon is significantly increasing during winters and annual scale due to mechanisms involving snow-albedo positive feedback, nighttime cloud cover, higher midtroposphere water vapor, aerosols' concentration, and land-use changes at higher altitudes (Pepin et al., 2019; You et al., 2017, 2020). The future temperature surge under the aforementioned phenomenon of EDW will pose severe impacts on the hydrology (Hasnain, 2014), ecosystems (Schickhoff et al., 2016) and human development (Shrestha et al., 2015) of the HKH region. . Kraaijenbrink et al. (2017) found that warming under RCP4.5, RCP6.0 and RCP8.5 scenarios in Asia will result in almost disappearance of ice by $49 \pm 7 \%, 51 \pm 6 \%$ and $64 \pm 5 \%$, respectively, by the end of the century. This is likely to cause rapid melting and depletion of glaciers under rapid warming will create serious implications like flash flooding, soil erosion and GLOFs over northern regions in near future and severe drought situation in far future. The resultant droughts and desertification across downstream regions will be more severe by the end of $21^{\text {st }}$ century (Abas et al., 2017; Ahmed et al., 2019b; Soncini et al., 2015). A remarkable water inflow into major reservoirs constructed downstream regions under glacier melting in the future will pose potential large-scale flooding during future spring, autumn and winter season (Haider et al., 2020).

The warming tendency across central Pakistan in this study yielded higher warming in the near and far future DJF season than in JJA under all SSP scenarios (Figures 3 and 4). The region consists of mostly plain terrain (Indus plains), deserts and hilly regions in western edges and over northern parts (Nawaz et al., 2019). This region accommodates most of country's population with vast glacier water irrigated lands and is major industrial hub of the country (Abbas, 2013). Over recent years, the winter warming rates have significantly increased across southern plains while summer mean temperature across northern and western hilly tracts of the region (Abbas, 2013; Nawaz et al., 2019). In the future annual and seasonal minimum temperature over the region is projected to increase significantly in southern Punjab region, conforming to our analysis (Fahad et al., 2016; Rasul et al., 2012; Sajjad and Ghaffar, 2019). The projected rise in temperature over central regions is caused by mainly caused by an increase in GHG emissions under chaotic hydrocarbon use in expanded industries, transportation system and other uses (Hussain et al., 2019). The population pressure, unplanned energy use, rapid and unplanned urbanization, improper waste management, unplanned industrialization, expanding transportation, change in agricultural practices and livestock management are further 
exacerbating the situation (Mumtaz et al., 2019). In addition to potential poverty rise under the reduction in agricultural productivity due to severe water shortage, the desertification and famine situation in the region and beyond is also inevitable (Shakoor et al., 2011).

A significant increase in DJF and JJA mean temperature, with a higher significant change rate (Table 2) in far future DJF than in JJA, is expected over southern Pakistan (Figures 3 and 4). The near and particularly far future DJF (Figure 7) project a significant temperature over the southeastern and southwestern corners over the south. While the far future JJA trends (Figure 8) also project a considerable increase in temperature over the southwestern fringes of the country. The southern region is already under extreme temperature changes in recent years, particularly over southeastern parts (Ahmed et al., 2019a; Ali et al., 2019). Moreover, Ikram et al. (2016), Rehman and Ali, (2018) and Sajjad and Ghaffar (2019) projected an increase in JJA mean temperature over southern Pakistan under RCP4.5 and RCP 8.5 after 2050 onwards to the end of the $21^{\text {st }}$ century. The southern region is mostly arid with plains and deserts in the centre, rugged mountains in northwestern fringes, and warm coastal regions (Rasul et al., 2012). The agriculture sector is the economic backbone, is severely under threat of backlash due to water scarcity under temperature rise and precipitation decreasing trends.

Further depletion of groundwater resources and others is eminent in future climatic conditions (Abbas et al., 2018). Over the southeastern and coastal regions of Pakistan, intense, prolonged-lasting, and frequent heatwaves, aridity and drought conditions are projected in the coming years (Haider and Adnan, 2014; Khan et al., 2019). The rising temperature in summer over southern regions may enhance the sand and dust storms intensity and frequency (Sajjad and Ghaffar, 2019).

The surface temperature severity to $\mathrm{CO}_{2}$ increase in the CMIP6 models has improved substantially (Tokarska et al., 2020; Forster et al., 2020). Such an increase is due to the varying representation of low cloud coverage and water content under strong warming with further enhanced sunlight absorption by CMIP6 models (Zelinka et al., 2020). Historical interdecadal mean surface temperature variability in CMIP6 models is greater and is associated with regional variability in tropical deep convective (forced) regions. This defines how, when, and where the warming effect will be felt since climate change progresses as a combination of internal and forced changes in the future (Parsons et al., 2020). The future warming estimates, uncertainties, and projection spread are better represented in mean and ranges (Brunner et al., 2020). 
Developing future predictions based on models' independence and performance skills for historical simulations is quite skillful in obtaining future changes estimates (Brunner et al., 2020; Eyring et al., 2019). Climate predictions being uncertain due to initial conditions and computational representational representation of equations in individual models can be better presented by the multimodel ensembles (Palmer et al., 2005).

The impacts of anthropogenic activities on surface temperature are essential in understanding the present and future climate change, environment, and sustainable development (Siddique et al., 2020). In Pakistan, rapid growth in transportation, industrialization, urbanization, deforestation, waste, agriculture, livestock, and energy use are the main drivers of GHG emissions and will result in countrywide temperature rise (Hussain et al., 2018). By 2050, GHG emissions contribution by energy and agriculture sector may rise to $59.1 \%, 38.2 \%$, while for industry, land use/land use change-forestry, and waste management sector will be $5.4 \%, 2.3$ $\%$ and $1.6 \%$ respectively (TCFD, 2018). Pakistan's population may grow up to 350 million by the year 2050, particularly in rural areas and around small cities (Survey, 2018). Due to promising economic opportunities, a large section population is bound to migrate to major commercial and industrial hubs (Abas et al., 2017; Abbas, 2013). Conclusively, future population pressure, fossil fuel-based industrialization, transportation, commercialization, and land use changes may intensify the GHG emissions and temperature rise over Pakistan. It is necessary to study the change and variability in drivers of GHG emission and temperature rise over Pakistan to understand future temperature warming-induced impacts in Pakistan. Moreover, it will also help develop a comprehensive, national, and regional level environmental, economic, disaster management, and climate change adaptation and mitigation policies.

\section{Conclusion}

The future seasonal mean temperature projections and trends are essential to identify its future spatiotemporal distribution and variability and its impact on the environment and humans. This study employed an ensemble of models to reduce output biases and errors in mean temperature changes and trends. Findings indicate increase in seasonal mean temperatures across Pakistan throughout the projection period, under all carbon emission scenarios.

The northern and central regions projected a significant increase in annual mean temperature; especially in the far future (figure 2). On seasonal scale, the northern regions 
projected the highest projected changes in DJF $\left(3.8^{\circ} \mathrm{C}, 5.1{ }^{\circ} \mathrm{C}\right.$ and $\left.6.5^{\circ} \mathrm{C}\right)$, followed by central regions $\left(3.8{ }^{\circ} \mathrm{C}, 4.9^{\circ} \mathrm{C}\right.$ and $\left.6.4{ }^{\circ} \mathrm{C}\right)$ for far future (figure 3) under all SSP scenarios. During the JJA (particularly far future), the central $\left(3.0^{\circ} \mathrm{C}, 4.4{ }^{\circ} \mathrm{C}\right.$ and $\left.5.4{ }^{\circ} \mathrm{C}\right)$ and southern $\left(2.7{ }^{\circ} \mathrm{C}, 3.3{ }^{\circ} \mathrm{C}\right.$ and $4.3{ }^{\circ} \mathrm{C}$ ) regions displayed the highest mean temperature positive changes (figure 4) under the SSP scenarios. Spatially, the northern region in near and far future DJF (figure 5) depicted the highest projections. While for JJA (figure 6), the central and southern regions projected the most remarkable positive changes in temperature.

Similarly, northern and central regions in the future are projected with higher increase in DJF (Table 2) temperature than in JJA. The central and southern regions anticipated a higher significant temperature increase in near future JJA (Table 2). While the southern regions overall projected the highest significant temperature increase in far future JJA (Table 2). The northern and central regions of Pakistan displayed highest trend increases in DJF under all SSP scenarios in spatial trend analysis (figure 7). However, during JJA, the central and southern regions projected higher temperature increase (figure 8). Further the far future JJA under SSP245 projected a decreasing trend over northern region, possibly due to aerosols' significant effect on model parameterization.

The abrupt trend shift analysis (figure S1 to S8) displayed the northern and central regions in near and far future DJF with the most of significant abrupt shifts and new trends beginnings. Most significant and abrupt trend changes in near future DJF (under SSP245 and SSP370) are also projected over northern regions. For near and far future JJA trend shifts under all SSPs, the southern and then central regions projected the most significant positive and abrupt trend shifts.

In near and far future seasonal temperature PDF analysis (figure 9 to 12), the DJF season displayed the maximum probability of positive change in mean temperature over the northern regions, with a remarkable change in the far future. While in JJA, the southern regions projected higher probability of temperature increase in near and far future.

This is the first study on temperature projections over Pakistan based on CMIP6 models. The outcome of this work is important in formulation of adaptation measures in temperature sensitive sectors as well as coming up with mitigation strategies to the possible impacts. Future climate scenarios with higher temperature rise in winter than summer supports the possibility of continued global warming. The overall increase in temperature is likely disrupt the hydrological 
cycle across the country and region at large, consequently affecting food productivity, environment, economy, trade and other sectors. The impacts of climate change are complex, multipronged and severe over time as they are interlinked under different mechanisms. Future studies focusing on response of specific sectors such as agriculture specifically crops farming are recommended to quantify the expected impact of the change in temperature.

Author Contributions: Conceptualization, R.K. and B.A.; methodology, R.K. and B.A.; software, R.K. and H.B.; validation, R.K., H.B., and B.A.; formal analysis, R.K., B.A and H.B.; investigation, G.T., N.R., V.O., and B.A.; resources, G.T., N.R.; data curation, B.A. and M.O.; writing - original draft preparation, R.K., B.A.,; writing-review and editing, R.K., G.T., B.A., L.F., H.B. H.N. and V.O.; visualization, R.K., H.B., and H.B..; supervision, G.T.; project administration, G.T., and B.A.; funding acquisition, G.T.

Declaration of Competing Interest: The authors declare that they have no competing interest, financial gains or personal relations that could have influenced the work reported in this paper.

Funding: National Key Research and Development Program of China (2017YFA0603804), National Natural Science Foundation of China (41575070) supported this work.

Acknowledgments: The authors acknowledge Nanjing University of Information Science and Technology (NUIST) for providing a favorable environment and infrastructural needs for conducting research. Authors are indebted to World Climate Research Program working group on coupled modeling for making the CMIP models' datasets freely available.

Conflicts of Interest: In a unanimous agreement, all authors declare no conflict of interest in the present study.

\section{References}

Abas, N., Kalair, A., Khan, N., Kalair, A.R., 2017. Review of GHG emissions in Pakistan compared to SAARC countries. Renew. Sustain. Energy Rev. 80, 990-1016. https://doi.org/10.1016/j.rser.2017.04.022

Abbas, F., 2013. Analysis of a historical (1981-2010) temperature record of the Punjab Province of Pakistan. Earth Interact. 17, 1-23. https://doi.org/10.1175/2013EI000528.1

Abbas, F., Rehman, I., Adrees, M., Ibrahim, M., Saleem, F., Ali, S., Rizwan, M., Salik, M.R., 2018a. Prevailing trends of climatic extremes across Indus-Delta of Sindh-Pakistan. Theor. Appl. Climatol. 131, 1101-1117. https://doi.org/10.1007/s00704-016-2028-y 
Abbas, F., Sarwar, N., Ibrahim, M., Adrees, M., Ali, S., Saleem, F., Hammad, H.M., $2018 b$. Patterns of climate extremes in the coastal and highland regions of Balochistan, Pakistan. Earth Interact. 22. https://doi.org/10.1175/EI-D-16-0028.1

Ahmad, I., Ambreen, R., Sun, Z., Deng, W., 2015. Winter-Spring Precipitation Variability in Pakistan. Am. J. Clim. Chang. 04, 115-139. https://doi.org/10.4236/ajcc.2015.41010

Ahmed, K., Sachindra, D.A., Shahid, S., Demirel, M.C., Chung, E. S., 2019a. Selection of multimodel ensemble of general circulation models for the simulation of precipitation and maximum and minimum temperature based on spatial assessment metrics. Hydrol. Earth Syst. Sci. 23, 4803-4824. https://doi.org/10.5194/hess-23-4803-2019

Ahmed, K., Shahid, S., Wang, X., Nawaz, N., Najeebullah, K., 2019b. Evaluation of gridded precipitation datasets over arid regions of Pakistan. Water (Switzerland) 11. https://doi.org/10.3390/w11020210

Ali, S., Eum, H.-I., Jaepil, C., Li, D., Khan, F., Dairaku, K., Shrestha, M.L., Hwang, S., Naseem, W., Khan, I.A., Fahad, S., 2019. Assessment of climate extremes in future projections downscaled by multiple statistical downscaling methods over Pakistan. Atmos. Res. 222, 114-133. https://doi.org/10.1016/J.ATMOSRES.2019.02.009

Ali, S., Li, D., Congbin, F., Khan, F., 2015. Twenty first century climatic and hydrological changes over Upper Indus Basin of Himalayan region of Pakistan. Environ. Res. Lett. https://doi.org/10.1088/1748-9326/10/1/014007

Almazroui, M., Saeed, F., Saeed, S., Nazrul Islam, M., Ismail, M., Klutse, N.A.B., Siddiqui, M.H., 2020a. Projected Change in Temperature and Precipitation Over Africa from CMIP6. Earth Syst. Environ. https://doi.org/10.1007/s41748-020-00161-X

Almazroui, M., Saeed, S., Saeed, F., Islam, M.N., Ismail, M., 2020b. Projections of Precipitation and Temperature over the South Asian Countries in CMIP6. Earth Syst. Environ. 4, 297320. https://doi.org/10.1007/s41748-020-00157-7

Amin, A., Nasim, W., Mubeen, M., Kazmi, D.H., Lin, Z., Wahid, A., Sultana, S.R., Gibbs, J., Fahad, S., 2017. Comparison of future and base precipitation anomalies by SimCLIM statistical projection through ensemble approach in Pakistan. Atmos. Res. 194, 214-225. https://doi.org/10.1016/j.atmosres.2017.05.002

Archer, D.R., Fowler, H.J., 2004. Spatial and temporal variations in precipitation in the Upper Indus Basin, global teleconnections and hydrological implications. Hydrol. Earth Syst. Sci. https://doi.org/10.5194/hess-8-47-2004

Asmat, U., Athar, H., Nabeel, A., Latif, M., 2018. An AOGCM based assessment of interseasonal variability in Pakistan. Clim. Dyn. 50, 349-373. https://doi.org/10.1007/s00382-017-3614-0

Athar, U.A.H., Latif, A.N.M., 2018. An AOGCM based assessment of interseasonal variability in Pakistan. Clim. Dyn. 50, 349-373. https://doi.org/10.1007/s00382-017-3614-0

Ayugi, B., Tan, G., Gnitou, G.T., Ojara, M., Ongoma, V., 2020. Historical evaluations and simulations of precipitation over East Africa from Rossby centre regional climate model. Atmos. Res. 232. https://doi.org/10.1016/j.atmosres.2019.104705

Ayugi, B.O., Tan, G., 2019. Recent trends of surface air temperatures over Kenya from 1971 to 2010. Meteorol. Atmos. Phys. 131, 1401-1413. https://doi.org/10.1007/s00703-018-0644-Z

Babar, Z.A., Zhi Xie-Fei, Ge, F., Riaz, M., Mahmood, A., Sultan, S., Shad, M.A., Aslam, C.M., Ahmad, M.F., 2016. Assessment of Southwest Asia Surface Temperature Changes: CMIP5 20 th and 21 st Century Simulations. Pakistan J. Meteorol. 13, 1-15.

Bessou, C., Ferchaud, F., Gabrielle, B., Mary, B., 2009. Biofuels, greenhouse gases and climate 
change. Sustain. Agric. 2, 365-468. https://doi.org/10.1007/978-94-007-0394-0_20

Boucharel, J., Dewitte, B., du Penhoat, Y., Garel, B., Yeh, S.W., Kug, J.S., 2011. ENSO nonlinearity in a warming climate. Clim. Dyn. 37, 2045-2065. https://doi.org/10.1007/s00382-011-1119-9

Brunner, L., Pendergrass, A., Lehner, F., Merrifield, A., Lorenz, R., Knutti, R., 2020. Reduced global warming from CMIP6 projections when weighting models by performance and independence. Earth Syst. Dyn. Discuss. 6, 1-23. https://doi.org/10.5194/esd-2020-23

Chatterjee, S., Khan, A., Akbari, H., Wang, Y., 2016. Monotonic trends in spatio-temporal distribution and concentration of monsoon precipitation (1901-2002), West Bengal, India. Atmos. Res. 182, 54-75. https://doi.org/10.1016/j.atmosres.2016.07.010

Chaudhry, Q.-Z., Mahmood, A., Rasul, G., Afzaal, M., 2009. Report on Climate Change Indicators of Pakistan. Tech. Rep. No. PMD-22/2009 1-44.

Cook, B.I., Mankin, J.S., Anchukaitis, K.J., 2018. Climate Change and Drought: From Past to Future. Curr. Clim. Chang. Reports 4, 164-179. https://doi.org/10.1007/s40641-018-0093-2

David Eckstein, M.-L.H. and M.W., 2019. Germanwatch, Greenwatch. https://doi.org/978-3943704-04-4

Eyring, V., Bony, S., Meehl, G.A., Senior, C.A., Stevens, B., Stouffer, R.J., Taylor, K.E., 2016. Overview of the Coupled Model Intercomparison Project Phase 6 (CMIP6) experimental design and organization. Geosci. Model Dev. 9, 1937-1958. https://doi.org/10.5194/gmd-9$\underline{1937-2016}$

Eyring, V., Cox, P.M., Flato, G.M., Gleckler, P.J., Abramowitz, G., Caldwell, P., Collins, W.D., Gier, B.K., Hall, A.D., Hoffman, F.M., Hurtt, G.C., Jahn, A., Jones, C.D., Klein, S.A., Krasting, J.P., Kwiatkowski, L., Lorenz, R., Maloney, E., Meehl, G.A., Pendergrass, A.G., Pincus, R., Ruane, A.C., Russell, J.L., Sanderson, B.M., Santer, B.D., Sherwood, S.C., Simpson, I.R., Stouffer, R.J., Williamson, M.S., 2019. Taking climate model evaluation to the next level. Nat. Clim. Chang. 9, 102-110. https://doi.org/10.1038/s41558-018-0355-y

Fahad, S., Ameen, A., Ahmad, A., Shahzad, B., Mirza, N., Amanullah, Hammad, H.M., Urich, P., Khan, M.N., Mubarak, H., Alharby, H., Ullah, A., Saud, S., Ata-Ul-Karim, S.T., Ahamd, S., Islam, F., Mubeen, M., Rehmani, M.I.A., Khaliq, T., Adnan, M., Ali, Q.S., Rasul, F., Wahid, A., Sarwar, S., Amin, A., Nasim, W., Wajid, A., 2016. Regional climate assessment of precipitation and temperature in Southern Punjab (Pakistan) using SimCLIM climate model for different temporal scales. Theor. Appl. Climatol. 131, 121-131. https://doi.org/10.1007/s00704-016-1960-1

Farooqi, A.B., Khan, A.H., Mir, H., 2005. Climate Change Perspective in Pakistan. Pakistan J. Meteorol. 2, 11-21.

Farooqui, M.N.I., Soomro, G.Y., 1984. An analysis of fertility change in Pakistan. Pak. Dev. Rev. 23, 225-238.

Fatima, E., Hassan, M., Hasson, S. ul, Ahmad, B., Ali, S.S.F., 2020. Future water availability from the western Karakoram under representative concentration pathways as simulated by CORDEX South Asia. Theor. Appl. Climatol. 141, 1093-1108. https://doi.org/10.1007/s00704-020-03261-w

Forster, P.M., Maycock, A.C., McKenna, C.M., Smith, C.J., 2020. Latest climate models confirm need for urgent mitigation. Nat. Clim. Chang. 10, 7-10. https://doi.org/10.1038/s41558-019-0660-0

Fowler, H.J., Archer, D.R., 2006. Conflicting signals of climatic change in the upper Indus Basin. J. Clim. 19, 4276-4293. https://doi.org/10.1175/JCLI3860.1 
Frankcombe, L.M., England, M.H., Mann, M.E., Steinman, B.A., 2015. Separating internal variability from the externally forced climate response. J. Clim. https://doi.org/10.1175/JCLI-D-15-0069.1

Grose, M.R., Narsey, S., Delage, F.P., Dowdy, A.J., Bador, M., Boschat, G., Chung, C., Kajtar, J.B., Rauniyar, S., Freund, M.B., Lyu, K., Rashid, H., Zhang, X., Wales, S., Trenham, C., Holbrook, N.J., Cowan, T., Alexander, L., Arblaster, J.M., Power, S., 2020. Insights From CMIP6 for Australia's Future Climate. Earth's 8 Futur. 8. https://doi.org/10.1029/2019ef001469

Guan, X., Huang, J., Guo, R., 2017. Changes in aridity in response to the global warming hiatus. J. Meteorol. Res. 31, 117-125. https://doi.org/10.1007/s13351-017-6038-1

Haider, H., Zaman, M., Liu, S., Saifullah, M., Usman, M., Chauhdary, J.N., Anjum, M.N., Waseem, M., 2020. Appraisal of Climate Change and Its Impact on Water Resources of Pakistan: A Case Study of Mangla Watershed. Atmosphere (Basel). 11, 1071. https://doi.org/10.3390/atmos11101071

Haider, S., Adnan, S., 2014. Classification and Assessment of Aridity Over Pakistan Provinces (1960-2009). Int. J. Environ. 3, 24-35. https://doi.org/10.3126/ije.v3i4.11728

Hansen, J., Ruedy, R., Sato, M., Lo, K., 2010. Global surface temperature change. Rev. Geophys. 48. https://doi.org/10.1029/2010RG000345

Hasnain, I.S., 2014. Hindu kush, karakorum, himalaya and tibetan plateau glaciers: Tipping point, in: Impact of Global Changes on Mountains: Responses and Adaptation. https://doi.org/10.1201/b17963

Hussain, M., Butt, A.R., Uzma, F., Ahmed, R., Rehman, A., Ali, M.U., Ullah, H., Yousaf, B., 2019. Divisional disparities on climate change adaptation and mitigation in Punjab, Pakistan: local perceptions, vulnerabilities, and policy implications. Environ. Sci. Pollut. Res. 26, 31491-31507. https://doi.org/10.1007/s11356-019-06262-z

Hussain, M., Liu, G., Yousaf, B., Ahmed, R., Uzma, F., Ali, M.U., Ullah, H., Butt, A.R., 2018. Regional and sectoral assessment on climate-change in Pakistan: Social norms and indigenous perceptions on climate-change adaptation and mitigation in relation to global context. J. Clean. Prod. 200, 791-808. https://doi.org/10.1016/j.jclepro.2018.07.272

Ikram, F., Afzaal, M., Bukhari, S.A.A., Ahmed, B., 2016. Past and Future Trends in Frequency of Heavy Rainfall Events over Pakistan. Pakistan J. Meteorol. 12, 57-78. http://www.pmd.gov.pk/rnd/rndweb/rnd_new/journal/vol12_issue24_files/5_Past_and_Futu re_Trends_in_Frequency_of_Heavy_Rainfall_Events_over_Pakistan_Final.pdf

IPCC, 2014. Synthesis Report. Contribution of Working Groups I, II and III to the Fifth Assessment Report of the Intergovernmental Panel on Climate Change [Core Writing Team, $\begin{array}{lllll}\text { R.K. Pachauri and L.A. Meyer } & \text { (eds.)]. IPCC } 151 .\end{array}$ https://doi.org/10.1017/CBO9781107415324

IPCC, 2018. An IPCC Special Report on the impacts of global warming of $1.5^{\circ} \mathrm{C}$. Intergov. Panel Clim. Chang. https://doi.org/10.1002/9780470996621.ch50

Iqbal, W., Zahid, M., 2014a. Historical and Future Trends of Summer Mean Air Temperature over South Asia. Pakistan J. Meteorol. 10, 67-74.

Jiménez-de-la-Cuesta, D., Mauritsen, T., 2019. Emergent constraints on Earth's transient and equilibrium response to doubled $\mathrm{CO} 2$ from post-1970s global warming. Nat. Geosci. 12, 902-905. https://doi.org/10.1038/s41561-019-0463-y

Karim, R., Tan, G., Ayugi, B., Babaousmail, H., Liu, F., 2020. Evaluation of Historical CMIP6 Model Simulations of Seasonal Mean Temperature over Pakistan during 1970-2014. 
Atmosphere (Basel). 11, 1005. https://doi.org/10.3390/atmos11091005

Kendall, M.G., 1975. Rank Correlation Methods, 4th ed. Griffin, London, pp. 202.

Khan, M.A., Khan, J.A., Ali, Z., Ahmad, I., Ahmad, M.N., 2016. The challenge of climate change and policy response in Pakistan. Environ. Earth Sci. 75, 1-16. https://doi.org/10.1007/s12665-015-5127-7

Khan, N., Shahid, S., Ahmed, K., Wang, X., Ali, R., Ismail, T., Nawaz, N., 2020. Selection of GCMs for the projection of spatial distribution of heat waves in Pakistan. Atmos. Res. 233. https://doi.org/10.1016/j.atmosres.2019.104688

Khan, N., Shahid, S., Ismail, T. bin, Wang, X.J., 2019. Spatial distribution of unidirectional trends in temperature and temperature extremes in Pakistan. Theor. Appl. Climatol. 136, 899-913. https://doi.org/10.1007/s00704-018-2520-7

Kraaijenbrink, P.D.A., Bierkens, M.F.P., Lutz, A.F., Immerzeel, W.W., 2017. Impact of a global temperature rise of 1.5 degrees Celsius on Asia's glaciers. Nature. https://doi.org/10.1038/nature23878

Leung, J.Y.S., Russell, B.D., Connell, S.D., 2019. Global Warming of 1.5C. an IPCC Special Report. Press. https://doi.org/10.1016/j.oneear.2019.10.025

Loo, Y.Y., Billa, L., Singh, A., 2015. Effect of climate change on seasonal monsoon in Asia and its impact on the variability of monsoon rainfall in Southeast Asia. Geosci. Front. 6, 817823. https://doi.org/10.1016/j.gsf.2014.02.009

Lupo, A., Kininmonth, W., 2013. Global Climate Models and Their Limitations. Clim. Chang. Reconsidered II Phys. Sci. 7-148.

Maher, N., Matei, D., Milinski, S., Marotzke, J., 2018. ENSO Change in Climate Projections: Forced Response or Internal Variability? Geophys. Res. Lett. https://doi.org/10.1029/2018GL079764

Mallika, M., Sundaram, S.M., Nirmala, M., 2015. Annual mean temperature prediction of India using K-Nearest Neighbour technique. Appl. Math. Sci. 9, 613-616. https://doi.org/10.12988/ams.2015.411953

Mann, H.B., 1945. Nonparametric Tests against Trend. Econometrica 13, 245. https://doi.org/10.2307/1907187

McSweeney, C., New, M., Lizcano, G., 2008. Climate Change Country Profiles Documentation. Natl. Commun. Support Program. 1-26.

Milinski, S., Maher, N., Olonscheck, D., 2019. How large does a large ensemble need to be? Earth Syst. Dyn. Discuss. 1-19. https://doi.org/10.5194/esd-2019-70

Mishra, V., Bhatia, U., Tiwari, A.D., 2020. Bias-corrected climate projections from Coupled Model Intercomparison Project-6 (CMIP6) for South Asia.

Mumtaz, M., Antonio Puppim de Oliveira, J., H. Ali, S., 2019. Climate Change Impacts and Adaptation in Agricultural Sector: The Case of Local Responses in Punjab, Pakistan. Clim. Chang. Agric. https://doi.org/10.5772/intechopen.83553

Nabeel, A., Athar, H., 2019. Observed, stochastically simulated, and projected precipitation variability in Pakistan. Theor. Appl. Climatol. 137, 2239-2256. https://doi.org/10.1007/s00704-018-2734-8

Nadia Rehman, M.A. and, Ali, S., 2018. Assessment of CMIP5 climate models over South Asia and climate change projections over Pakistan under representative concentration pathways. Int. J. Glob. Warm. 16, 381. https://doi.org/10.1504/ijgw.2018.10017114

Nasim, W., Amin, A., Fahad, S., Awais, M., Khan, N., Mubeen, M., Wahid, A., Rehman, M.H., Ihsan, M.Z., Ahmad, S., Hussain, S., Mian, I.A., Khan, B., Jamal, Y., 2018. Future risk 
assessment by estimating historical heat wave trends with projected heat accumulation using SimCLIM climate model in Pakistan. Atmos. Res. 205, 118-133. https://doi.org/10.1016/j.atmosres.2018.01.009

Nawaz, Z., Li, X., Chen, Y., Guo, Y., Wang, X., Nawaz, N., 2019. Temporal and spatial characteristics of precipitation and temperature in Punjab, Pakistan. Water (Switzerland) 11. https://doi.org/10.3390/w11091916

O’Neill, B.C., Kriegler, E., Riahi, K., Ebi, K.L., Hallegatte, S., Carter, T.R., Mathur, R., van Vuuren, D.P., 2014. A new scenario framework for climate change research: The concept of shared socioeconomic pathways. Clim. Change 122, 387-400. https://doi.org/10.1007/s10584-013-0905-2

O’Neill, B.C., Tebaldi, C., Van Vuuren, D.P., Eyring, V., Friedlingstein, P., Hurtt, G., Knutti, R., Kriegler, E., Lamarque, J.F., Lowe, J., Meehl, G.A., Moss, R., Riahi, K., Sanderson, B.M., 2016. The Scenario Model Intercomparison Project (ScenarioMIP) for CMIP6. Geosci. Model Dev. 9, 3461-3482. https://doi.org/10.5194/gmd-9-3461-2016

Ongoma, V., Chen, H., Gao, C., Nyongesa, A.M., Polong, F., 2018a. Future changes in climate extremes over Equatorial East Africa based on CMIP5 multimodel ensemble. Nat. Hazards 90, 901-920. https://doi.org/10.1007/s11069-017-3079-9

Ongoma, V., Chena, H., Gaoa, C., 2018b. Projected changes in mean rainfall and temperature over east Africa based on CMIP5 models. Int. J. Climatol. 38, 1375-1392. https://doi.org/10.1002/joc.5252

Palmer, T.N., Shutts, G.J., Hagedorn, R., Doblas-Reyes, F.J., Jung, T., Leutbecher, M., 2005. Representing model uncertainty in weather and climate prediction. Annu. Rev. Earth Planet. Sci. https://doi.org/10.1146/annurev.earth.33.092203.122552

Parsons, L.A., Brennan, M.K., Wills, R.C.J., Proistosescu, C., 2020. Magnitudes and Spatial Patterns of Interdecadal Temperature Variability in CMIP6. Geophys. Res. Lett. https://doi.org/10.1029/2019GL086588

Pepin, N., Bradley, R.S., Diaz, H.F., Baraer, M., Caceres, E.B., Forsythe, N., Fowler, H., Greenwood, G., Hashmi, M.Z., Liu, X.D., Miller, J.R., Ning, L., Ohmura, A., Palazzi, E., Rangwala, I., Schöner, W., Severskiy, I., Shahgedanova, M., Wang, M.B., Williamson, S.N., Yang, D.Q., 2015. Elevation-dependent warming in mountain regions of the world. Nat. Clim. Chang. 5, 424-430. https://doi.org/10.1038/nclimate2563

Pepin, N., Deng, H., Zhang, H., Zhang, F., Kang, S., Yao, T., 2019. An Examination of Temperature Trends at High Elevations Across the Tibetan Plateau: The Use of MODIS LST to Understand Patterns of Elevation-Dependent Warming. J. Geophys. Res. Atmos. 124, 5738-5756. https://doi.org/10.1029/2018JD029798

Perkins-Kirkpatrick, S.E., Gibson, P.B., 2018. Erratum: Author Correction: Changes in regional heatwave characteristics as a function of increasing global temperature (Scientific reports (2017) 71 (12256)). Sci. Rep. 8, 4652. https://doi.org/10.1038/s41598-018-23085-z

Ramesh, K. V., Goswami, P., 2014. Assessing reliability of regional climate projections: The case of Indian monsoon. Sci. Rep. 4. https://doi.org/10.1038/srep04071

Rangwala, I., Miller, J.R., Russell, G.L., Xu, M., 2010. Using a global climate model to evaluate the influences of water vapor, snow cover and atmospheric aerosol on warming in the Tibetan Plateau during the twenty-first century. Clim. Dyn. 34, 859-872. https://doi.org/10.1007/s00382-009-0564-1

Rasul, G., Afzal, M., Zahid, M., Bukhari, S.A.A., 2012b. Climate Change in Pakistan: Focused on Sindh Province, Pakistan Meteorological Department Technical Report No. PMD 
25/2012. https://doi.org/10.13140/2.1.2170.6560

Sajjad, H., Ghaffar, A., 2019. Observed, simulated and projected extreme climate indices over Pakistan in changing climate. Theor. Appl. Climatol. 137, 255-281. https://doi.org/10.1007/s00704-018-2573-7

Sarfaraz, S., 2014. The Sub-Regional Classification of Pakistan's Winter Precipitation Based On Principal Components Analysis. Pakistan J. Meteorol. 10, 57-66.

Schickhoff, U., Singh, R.B., Mal, S., 2016. Climate change and dynamics of glaciers and vegetation in the Himalaya: An overview, in: Climate Change, Glacier Response, and Vegetation Dynamics in the Himalaya: Contributions Toward Future Earth Initiatives. https://doi.org/10.1007/978-3-319-28977-9_1

Sen, P.K., 1968. Estimates of the Regression Coefficient Based on Kendall's Tau. J. Am. Stat. Assoc. 63, 1379-1389. https://doi.org/10.1080/01621459.1968.10480934

Shakoor, U., Saboor, A., Ali, I., Mohsin, A.Q., 2011. Impact of climate change on agriculture: Empirical evidence from arid region. Pakistan J. Agric. Sci. 48, 327-333.

Shrestha A, Agrawal N, Alfthan B, Bajracharya S, Maréchal J and van Oort B (2015). The Himalayan Climate and Water Atlas: Impact of climate change on water resources in five of Asia's major river basins. In ICIMOD, GRID-Arendal and CICERO

Siddique, M.A., Dongyun, L., Li, P., Rasool, U., Khan, T.U., Farooqi, T.J.A., Wang, L., Fan, B., Rasool, M.A., 2020. Assessment and simulation of land use and land cover change impacts on the land surface temperature of Chaoyang District in Beijing, China. Peer J. https://doi.org/10.7717/peerj.9115

Soncini, A., Bocchiola, D., Confortola, G., Bianchi, A., Rosso, R., Mayer, C., Lambrecht, A., Palazzi, E., Smiraglia, C., Diolaiuti, G., 2015. Future hydrological regimes in the upper Indus basin: A case study from a high-altitude glacierized catchment. J. Hydrometeorol. 16, 306-326. https://doi.org/10.1175/JHM-D-14-0043.1

Stocker, T.F., Qin, D., Plattner, G.K., Tignor, M.M.B., Allen, S.K., Boschung, J., Nauels, A., Xia, Y., Bex, V., Midgley, P.M., 2013. Climate change 2013 the physical science basis: Working Group I contribution to the fifth assessment report of the intergovernmental panel on climate change, Climate Change 2013 the Physical Science Basis: Working Group I Contribution to the Fifth Assessment Report of the Intergovernmental Panel on Climate Change. https://doi.org/10.1017/CBO9781107415324

Survey, P.E., 2018. Population, Labour Force \& Employment. Pakistan Econ. Surv. 2017-18.

TCFD, 2018. Task Force on Financial Disclosures: Status Report. Task Force Clim. Financ. Discl.

Tokarska, K.B., Stolpe, M.B., Sippel, S., Fischer, E.M., Smith, C.J., Lehner, F., Knutti, R., 2020. Past warming trend constrains future warming in CMIP6 models. Sci. Adv. 6. https://doi.org/10.1126/sciadv.aaz9549

Trenberth, K.E., 2011. Changes in precipitation with climate change. Clim. Res. 47, 123-138. https://doi.org/10.3354/cr00953

Ullah, S., You, Q., Ali, A., Ullah, W., Jan, M.A., Zhang, Y., Xie, W., Xie, X., 2019a. Observed changes in maximum and minimum temperatures over China- Pakistan economic corridor during 1980-2016. Atmos. Res. 216, 37-51. https://doi.org/10.1016/j.atmosres.2018.09.020

Ullah, S., You, Q., Ullah, W., Hagan, D.F.T., Ali, A., Ali, G., Zhang, Y., Jan, M.A., Bhatti, A.S., Xie, W., 2019b. Daytime and nighttime heat wave characteristics based on multiple indices over the China-Pakistan economic corridor. Clim. Dyn. 53, 6329-6349. https://doi.org/10.1007/s00382-019-04934-7 
Vermeulen, J.L., Hillebrand, A., Geraerts, R., 2017. A comparative study of k-nearest neighbour techniques in crowd simulation. Comput. Animat. Virtual Worlds 28. https://doi.org/10.1002/cav.1775

Watterson, I.G., 2008. Calculation of probability density functions for temperature and precipitation change under global warming. J. Geophys. Res. Atmos. 113. https://doi.org/10.1029/2007JD009254

Wu, G., Liu, Y., 2016. Impacts of the Tibetan Plateau on Asian Climate. Meteorol. Monogr. 56, 7.1-7.29. https://doi.org/10.1175/amsmonographs-d-15-0018.1

Wyser, K., Kjellström, E., Koenigk, T., Martins, H., Döscher, R., 2020. Warmer climate projections in EC-Earth3-Veg: The role of changes in the greenhouse gas concentrations from CMIP5 to CMIP6. Environ. Res. Lett. https://doi.org/10.1088/1748-9326/ab81c2

Yang, C., Schneider, S.H., 2003. Global Carbon Dioxide Emissions Scenarios: Sensitivity to Social and Technological Factors in Three Regions. Mitig. Adapt. Strateg. Glob. Chang. 2, 373-404. https://doi.org/10.1023/b:miti.0000004666.40140.ad

You, Q., Chen, D., Wu, F., Pepin, N., Cai, Z., Ahrens, B., Jiang, Z., Wu, Z., Kang, S., AghaKouchak, A., 2020. Elevation dependent warming over the Tibetan Plateau: Patterns, mechanisms and perspectives. Earth-Science Rev. 210, 103349. https://doi.org/10.1016/j.earscirev.2020.103349

You, Q.L., Ren, G.Y., Zhang, Y.Q., Ren, Y.Y., Sun, X.B., Zhan, Y.J., Shrestha, A.B., Krishnan, R., 2017. An overview of studies of observed climate change in the Hindu Kush Himalayan (HKH) region. Adv. Clim. Chang. Res. 8, 141-147. https://doi.org/10.1016/j.accre.2017.04.001

Zelinka, M.D., Myers, T.A., McCoy, D.T., Po-Chedley, S., Caldwell, P.M., Ceppi, P., Klein, S.A., Taylor, K.E., 2020. Causes of Higher Climate Sensitivity in CMIP6 Models. Geophys. Res. Lett. 47. https://doi.org/10.1029/2019GL085782 